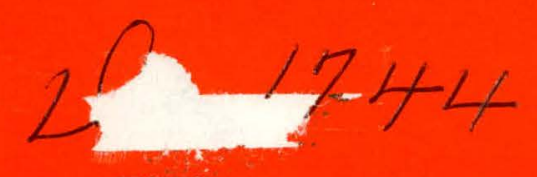

\title{
Investigation of Simple Daily Solar Radiation Models Suitable for Use in the Design of Solar Heating Systems
}
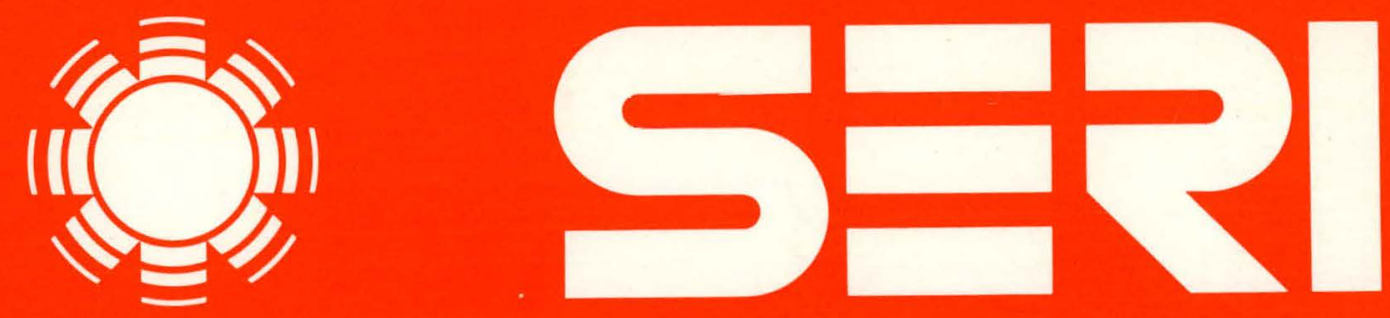

Solar Energy Research Institute

A Division of Midwest Rescarch Institute

1617 Cole Boulevard

Golden, Colorado 80401

Operated for the

U.S. Department of Energy

under Contract No. EG-77-C-01-4042 


\section{DISCLAIMER}

This report was prepared as an account of work sponsored by an agency of the United States Government. Neither the United States Government nor any agency Thereof, nor any of their employees, makes any warranty, express or implied, or assumes any legal liability or responsibility for the accuracy, completeness, or usefulness of any information, apparatus, product, or process disclosed, or represents that its use would not infringe privately owned rights. Reference herein to any specific commercial product, process, or service by trade name, trademark, manufacturer, or otherwise does not necessarily constitute or imply its endorsement, recommendation, or favoring by the United States Government or any agency thereof. The views and opinions of authors expressed herein do not necessarily state or reflect those of the United States Government or any agency thereof. 


\section{DISCLAIMER}

Portions of this document may be illegible in electronic image products. Images are produced from the best available original document. 


\author{
Printed in the United States of America \\ Available from: \\ National Technical Information Service \\ U.S. Department of Commerce \\ 5285 Port Royal Road \\ Springfield, VA 22161 \\ Price: \\ Microfiche $\$ 3.00$ \\ Printed Copy $\$ 4.50$
}

\begin{abstract}
NOTICE
This report was prepared as an account of work sponsored by the United States Government. Neither the United States nor the United States Department of Energy, nor any of their employees, nor any of their contractors, subcontractors, or their employees, makes any warranty, express or implied, or assumes any legal liability or responsibility for the accuracy, completeness or usefulness of any information, apparatus, product or process disclosed, or represents that its use would not infringe privately owned rights.
\end{abstract}


INVESTIGATION OF SIMPLE DAILY

SOLAR RADIATION MODELS

SUITABLE FOR USE IN THE DESIGN

OF SOLAR HEATING SYSTEMS

SANFORD SILLMAN

AUgust 1980

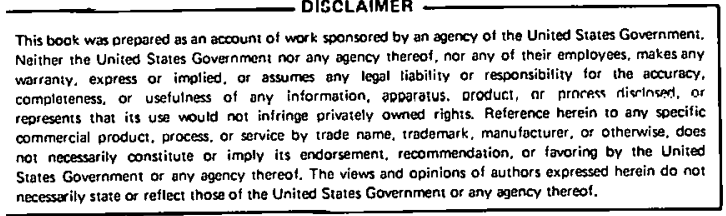

PREPAREd UNDER TASK NO. 5525.00

\section{Solar Energy Research Institute}

A Division of Midwest Research Institute

1617 Cole Boulevard

Golden, Colorado 80401

Prepared for the

U.S. Department of Energy

Contract No: EG-77-C-01-4042 


\section{THIS PAGE}

\section{WAS INTENTIONALLY \\ LEFT BLANK}


$\left(\begin{array}{c}10 \\ 8\end{array}\right.$

FOREWORD

This document is based on research done by the author as a consultant to Gordon Tully of Massdesign Architects. It describes a simple procedure for modeling daily solar radiation that can be used in the design of solar heating systems. The data in this report provide support for projects in the Building Systems Development Branch of the Solar Energy Research Institute, including analysis of annual storage systems and development of design tools.

The author wishes to express appreciation to Frank Baylin and Michael Holtz, both of whom reviewed the completed document and provided valuable advice in its preparation, and to Gordon Tully, who collaborated in the development of the original concept.

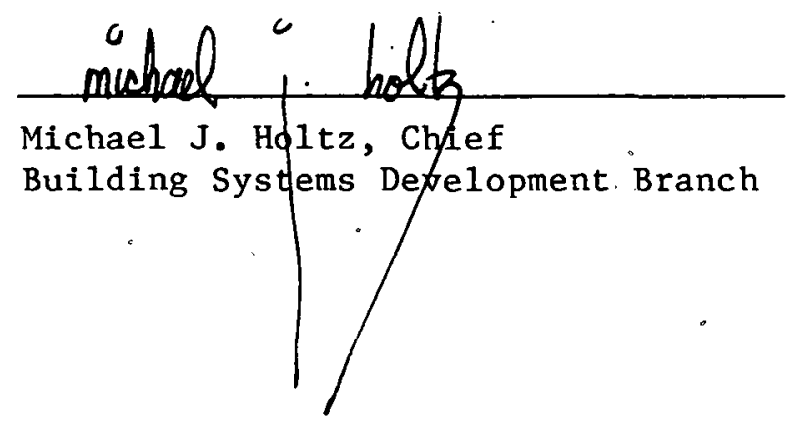

Approved for:

SOLAR EENETEGY RESEARCH INSTITUTE

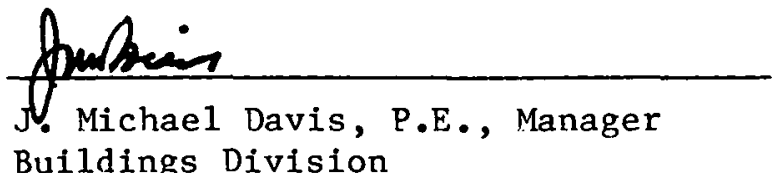


THIS PAGE

\section{WAS INTENTIONALLY LEFT BLANK}




\section{SUMMARY}

Solar heating system simulations typically require the use of hourly weather data. While these simulations are highly accurate, they are only of use to designers who have access to a main-line computer. A simpler alternative would be to model dally system performance using daily rather than hourly weather data. This approach has been used in simulations such as TEANET which are designed for use on programmable calculators. Such programs are generally intended to simulate a day or week rather than a full year.

This paper investigates simulation of the annual performance of solar heating systems based on daily weather data. If accurate, such a simulation would require only 1460 data inputs for a year's run, instead of 10,000 inputs for an hourly simulation, and could be run easily on a microcomputer.

The simulations investigated here are all based on sinusoidal models for daily solar radiation. The most accurate radiation model requires as input data the maximum and total insolation for each day. The maximum and dally total insolation uniquely determine a sine curve, which is taken as the daily solar radiation pattern. The more common approach of modeling radiation by a sine curve with frequency based on day length is found to be inaccurate. Since maximum dafly insolation is rarely tabulated, alternate models for daily radiation requiring only the total daily insolation as input are also investigated.

A theoretical comparison is made between dally radiation model results and hourly data for each day of the year in ten cities. In addition, performance of the dally radiation models in active solar heating system simulation is assessed. It is found that when an hourly step simulation is performed using daily weather data and a sinusoidal model for radiation in place of hourly data, the resulting error is always less than $1.5 \%$. Use of a daily step simulation is found to be accurate for evacuated tube collector systems or for flat plate collector systems with large storage capacity (enough to meet the load of three days or more). For flat plate collector systems wi.th smaller storage, dafly step simulation underestimates annual system performance by up to $5 \%$. Simulation results using daily weather data also compare favorably with f-chart and with designs for annual storage solar heating systems.

It is concluded that the use of dafly weather data with a radiation model is of sufficient accuracy to be used in place of hourly weather data in the simulation of active solar heating systems. It is also concluded that efforts should be made to collect and tabulate daily total and maximum insolation data on which the datily radiation model is based. 


\section{THIS PAGE}

\section{WAS INTENTIONALLY LEFT BLANK}


1.0 Introduction....................................... 1

2.0 Simple Solar Radiation Models............................ 3

2.1 Simulations with the Radiation Mode1..................... 8

2.2 Validation. ...................................... 10

3.0. Modified Dally Radiation Models............................ 13

3.1 A Combined Mode1 Based on Both QMAX and Day Length........... 13

3.2 A Modified Model Based on Maximum Insolation................ 14

3.3 A Modified Model Based on Day Length...................... 14

4.0 Results of Daily Simulation............................ 17

5.0 Conclusion........................................ 23

6.0 References......................................... 25

Appendix A. Collector Utilization for Varying $\mathrm{H}_{\mathrm{c}}$ Levels, Typical Meteorological Year, Madison, Wis.: 5 Tables.............. A-1

Appendix B. Solar Heating Design with the Dally Algorithms........... B-1 


\section{LIST OF FIGURES}

Page

2-1 Dally Solar Radiation Patterns............................. 4-7

2-2 Illustration of Critical Levels and Solar Utilization........... 11

3-1 Daily Solar Radiation Patterns, from Modifled Mode1............. 15

4-1 Results of Solar Heating System Simulations................... 18

4-2 Comparison of Simulation Results from Figure 4-1 with f-chart...... 19

4-3 Design for Two-Tank System............................. 21

B-1 Flowchart of Simulation with Hourly Invervals.................. B-4

B-2 Flowchart of Daily Simulation............................ B-6 
SECTION 1.0

INTRODUCTION

The design of solar heating systems is difficult because system operation typically varies from hour to hour, in response to insolation. As a result, design methods often are based on hour-by-hour simulation, requiring hourly weather data. While simulations such as TRNSYS are highly accurate, they are of limited usefulness to designers because they require access to a main line computer. The alternative to hourly simulation is a design code, such as $\mathrm{f}$ chart, or solar load ratio for passive design. These codes are easy to use but are limited in applicability and of ten cannot reflect innovative designs.

This paper presents an investigation of sinusoldal models for daily solar radiation that could be used in a day-by-day simulation of solar heating systems. If accurate, this type of simulation would require on $1 y, 1,000-1,500$ data inputs for a complete year's run, and could be run on a microcomputer. Hourly simulations, by contrast, require over 10,000 data inputs for a year's run. Simple dally radiation models already have been used in simulations designed for programmable calculators, such as the TI-59. However, these simulations are almed at modeling daily system performance rather than accurately reflecting annual performance. The accuracy of dally radiation models for annual runs will be the subject of this paper.

Accuracy of the daily radiation models wil be assessed in two ways. First, an hour-by-hour comparison will be made to Typical Meteorological Year weather data. Second, results of actual system simulations will be presented and compared to results of standard hourly simulations. 


\section{SECTION 2.0}

\section{SIMPLE SOLAR RADIATION MODELS}

The simplest daily radiation model is a sinusoidal function of the form:

$$
Q(t)=Q_{k} \cos \omega t
$$

where $t$ is the time of day in hours with solar noon set at zero. The parameters $Q_{k}$ and $\omega$ are to be set based on daily radiation data.

There are two independent ways of setting $Q_{k}$ and $\omega$. One method is to set $\omega$ (in radians) accurately based on day length $\left(t_{D}\right)$ :

$$
\omega=\pi / t_{D}
$$

Calculation of the day length, $t_{D}$. will be presented in Appendix $B$. The other parameter, $Q_{k}$, is set so that the total radiation equals the actual total radiation from weather data. Thus,

$$
Q_{k}=\frac{1}{2} \omega \cdot \mathrm{QTOT}
$$

QTOT will be used henceforth for the actual daily total radiation from weather data.

The second method is to set $Q_{k}$ to accurately reflect the actual daily maximum hourly insolation (henceforth known as QMAX). Maximum insolation is found from the hourly Typical Meteorological Year data, with the daily maximum (QMAX) set equal to the maximum hourly insolation during the day. In this method, $Q_{k}$ is set equal to QMAX, and $\omega$ is calculated to assure that total daily radiation equals the actual total (QTOT). Thus,

$$
\begin{aligned}
\mathrm{Q}_{\mathrm{k}} & =\mathrm{QMAX} \\
\omega & =2 \text { QMAX/QTOT }
\end{aligned}
$$

These two models will be referred to below as the day-length model and the QMAX model, respectively.

At first glance, approximation of daily radiation by a sine function appears accurate on clear days but may not adequately model the intermittent radiation pattern of cloudy days. Figure 2-1 indicates how the radiation models compare with weather data. The figures at the right in Figure 2-1 give the hour-byhour insolation for four January days in Boulder, Colo. In the " $b$ " and " $c$ " figures at the left, hourly insolation is rearranged out of the proper time sequence, with the hour of maximum insolation presented at noontime and hours of successively smaller insolation plotted as progressively further from noon. Superimposed on the modified hourly insolation pattern are the calculated sinusoidal radiation functions. A comparison of Figure 2-la with Figures 2-1 b and $c$ shows how irregular radiation patterns may in truth be modeled accurately by a sinusoidal function. 


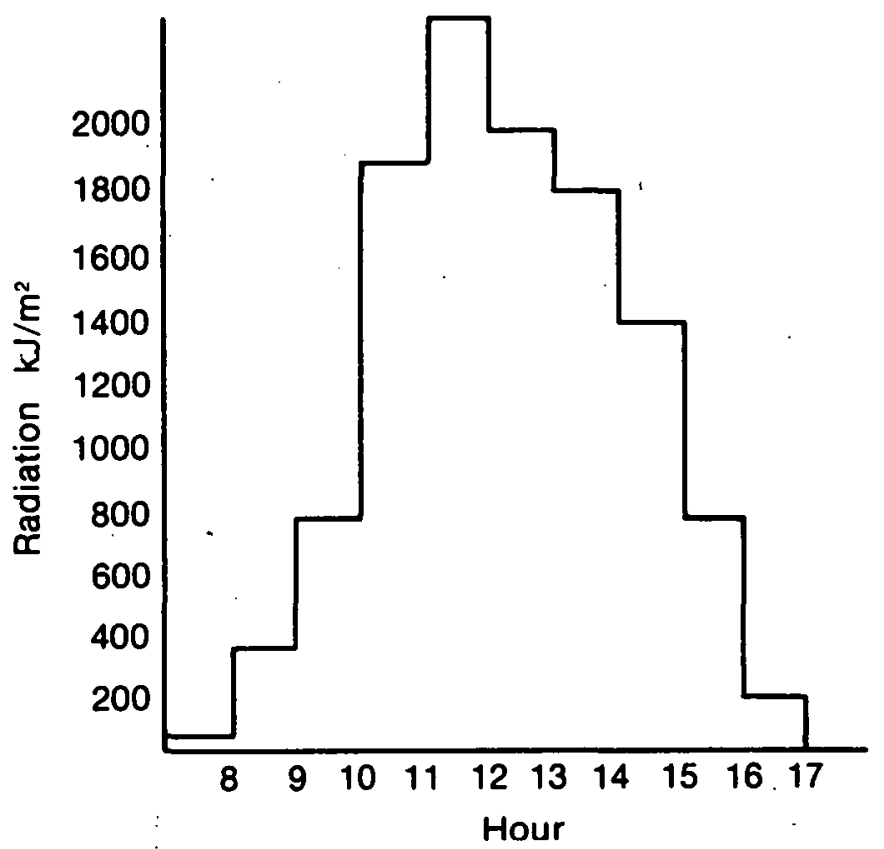

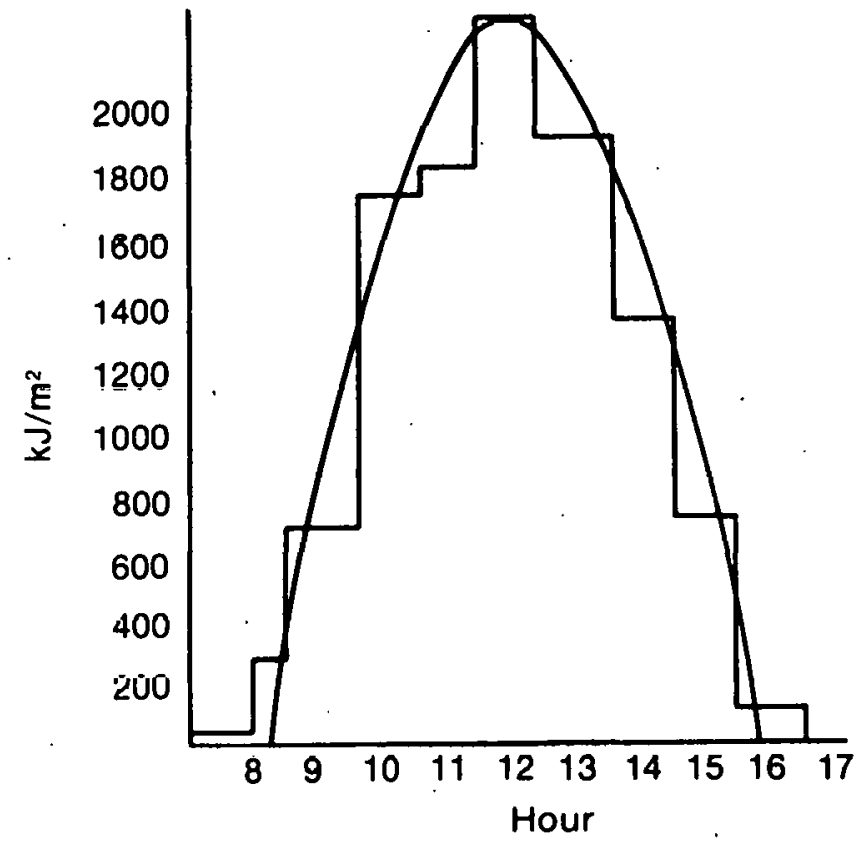

(b) (a)

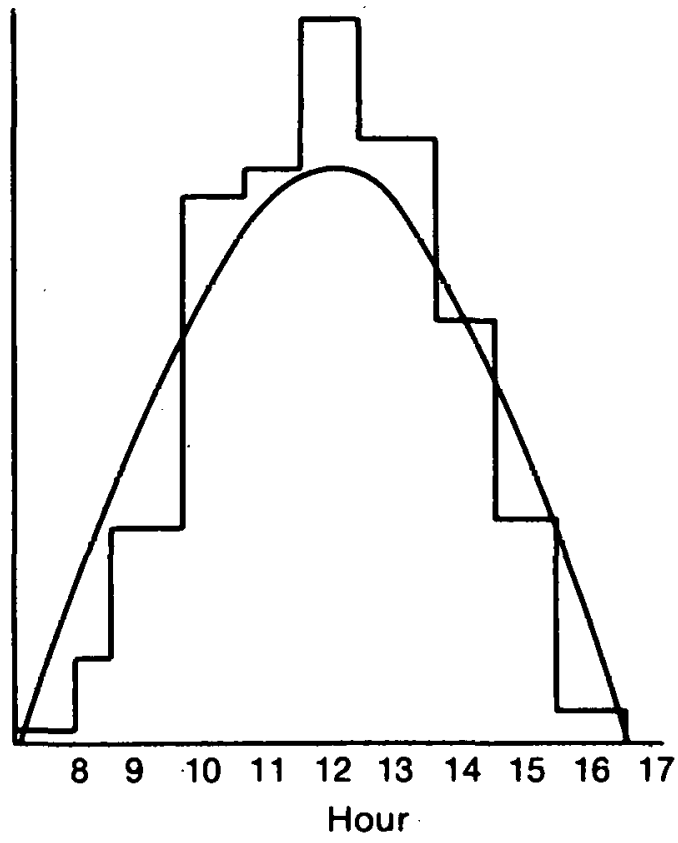

(c)

QMAX $=2299 \mathrm{~kJ} / \mathrm{m}^{2}$ QTOT $=10941 \mathrm{~kJ} / \mathrm{m}^{2}$

I Sunny Day

The "a" figures (top) give hourly insolation data for each of four January days in Boulder, Colo. (from Duffie and Beckman, 1974). The " $b$ " and " $c$ " figures (bottom) give the hourly insolation pattern for the same four days rearranged with maximum hourly insolation at the center and minimum insolation at the edges. Superimposed on the insolation pattern are the functions for insolation generated by the QMAX daily model (Figure $b$ ) and by the day-length model (Figure c).

Figure 2-1. Daily Solar Radiation Patterns 


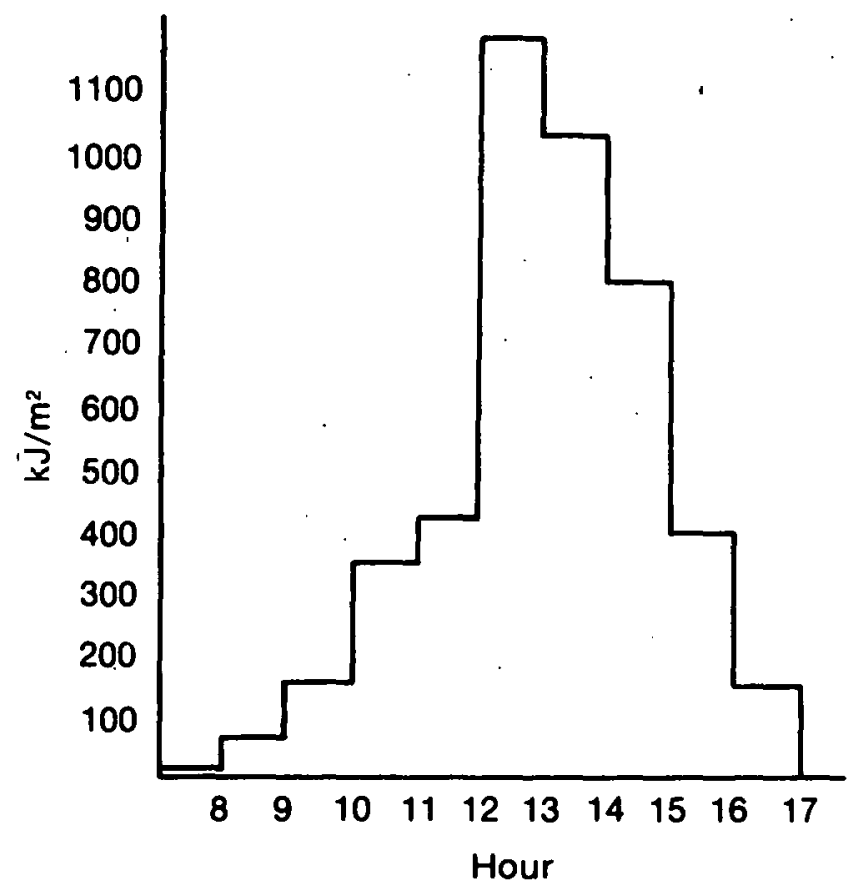

(a)

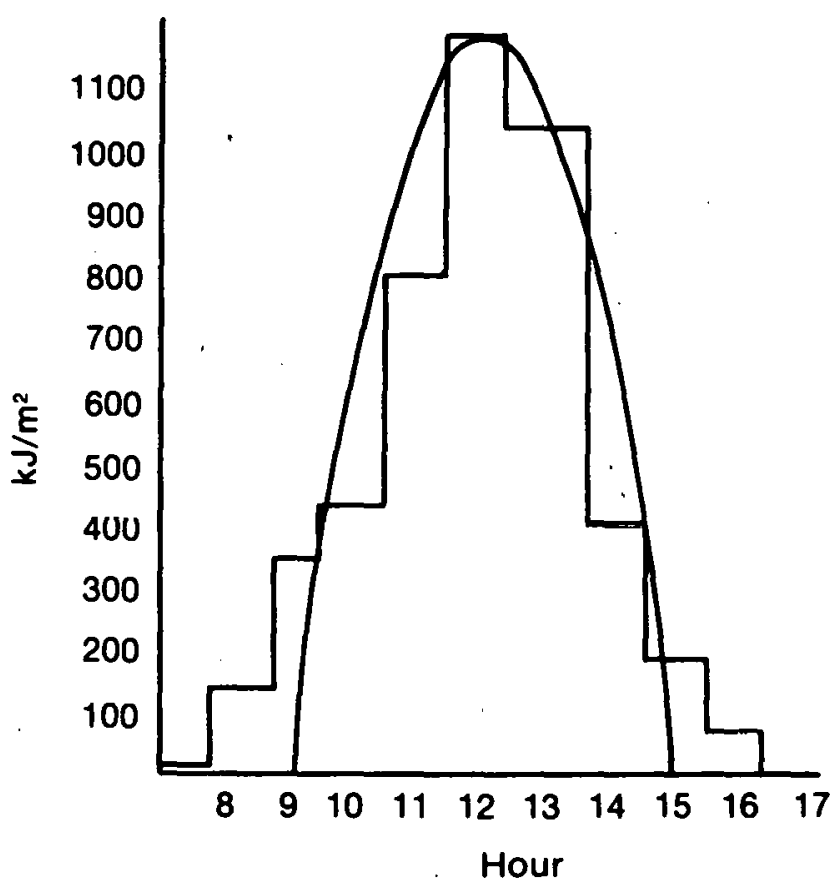

(b)

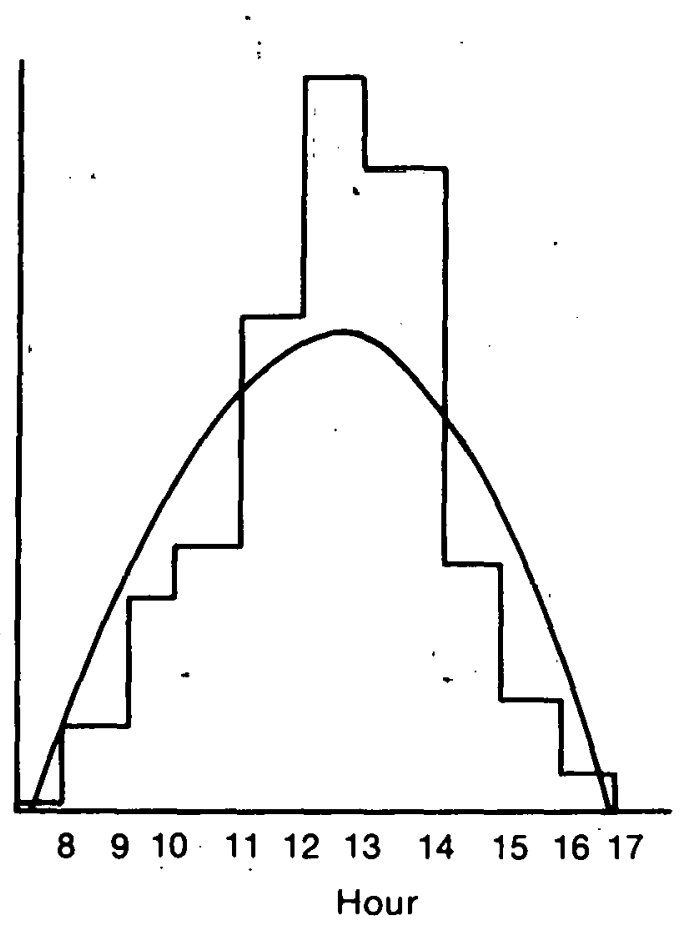

(c)

QTOT $=4488$ QMAX $=1185 \mathrm{~kJ} / \mathrm{m}^{2}$

II Partly Sunny Day

Figure 2-1. Daily Solar Radiation Palterns (cont.) 


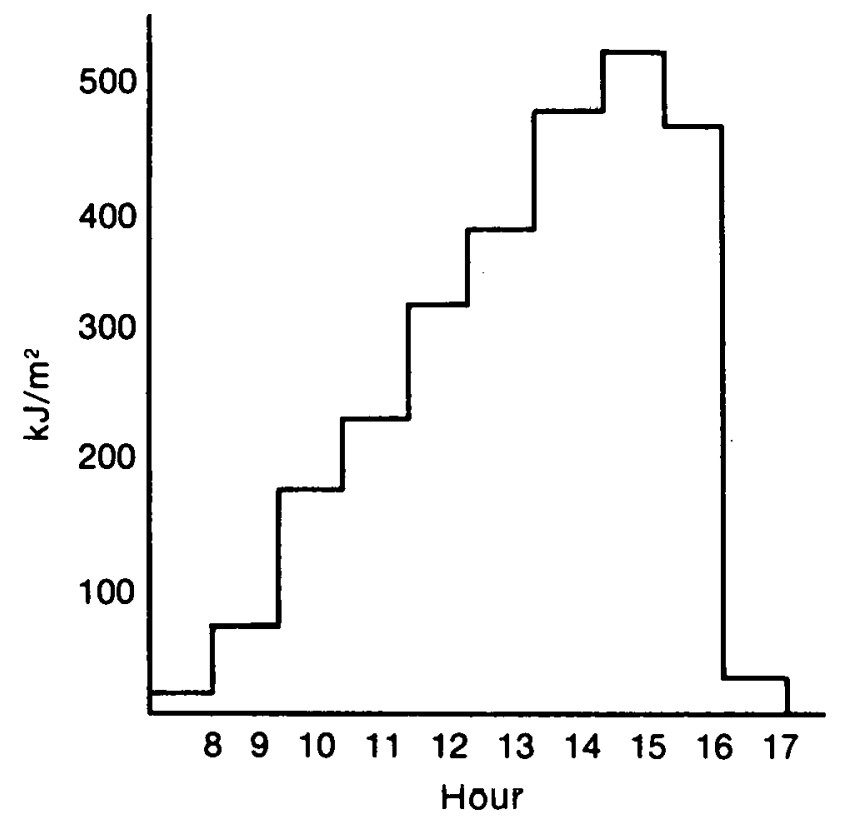

(a)

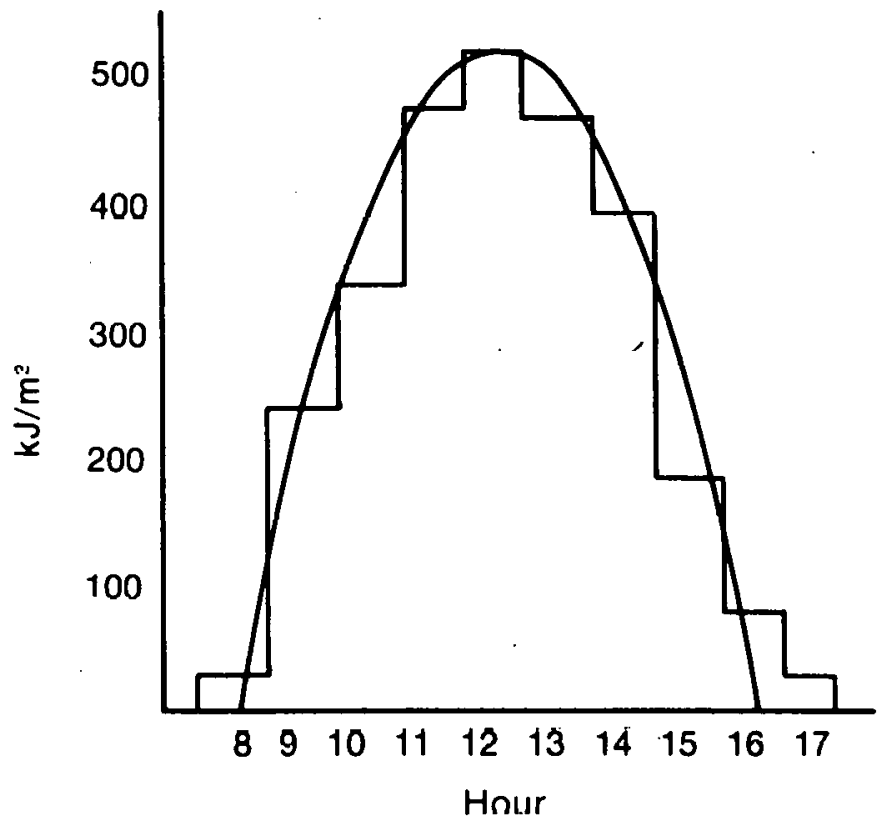

(b)

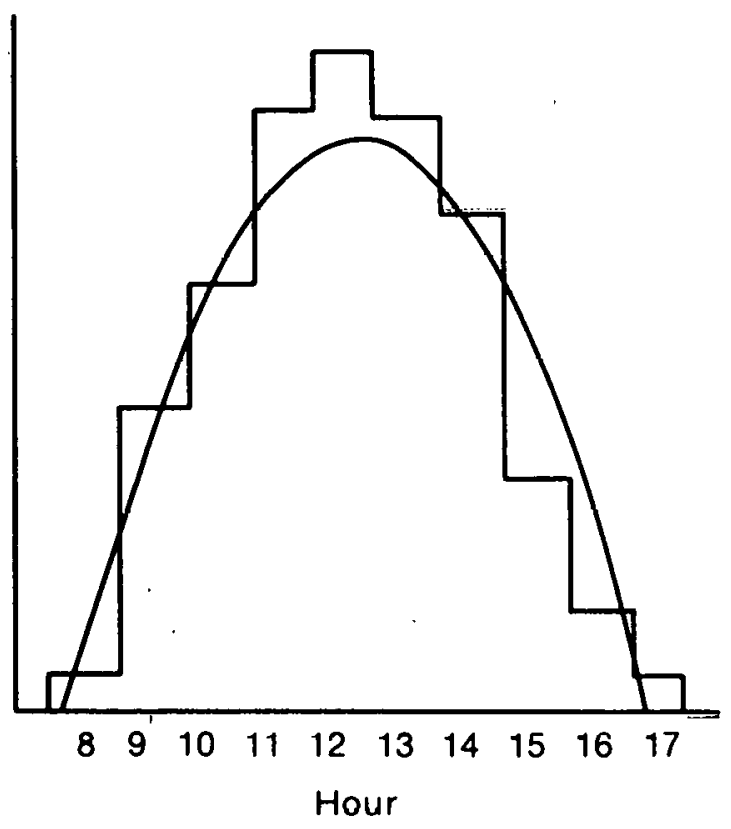

(c)

OMAX $=532$ OTOT $=2738 \mathrm{~kJ} / \mathrm{m}^{2}$

III Partly Cloudy Day

Figure 2-1. Daily Solar Radiation Patterns (cont.) 


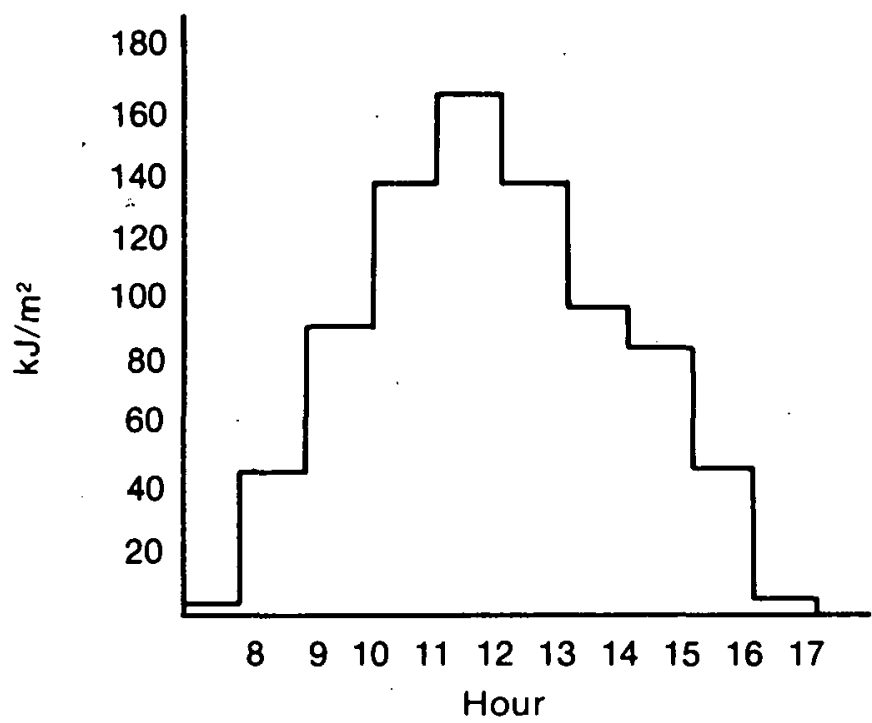

(a)

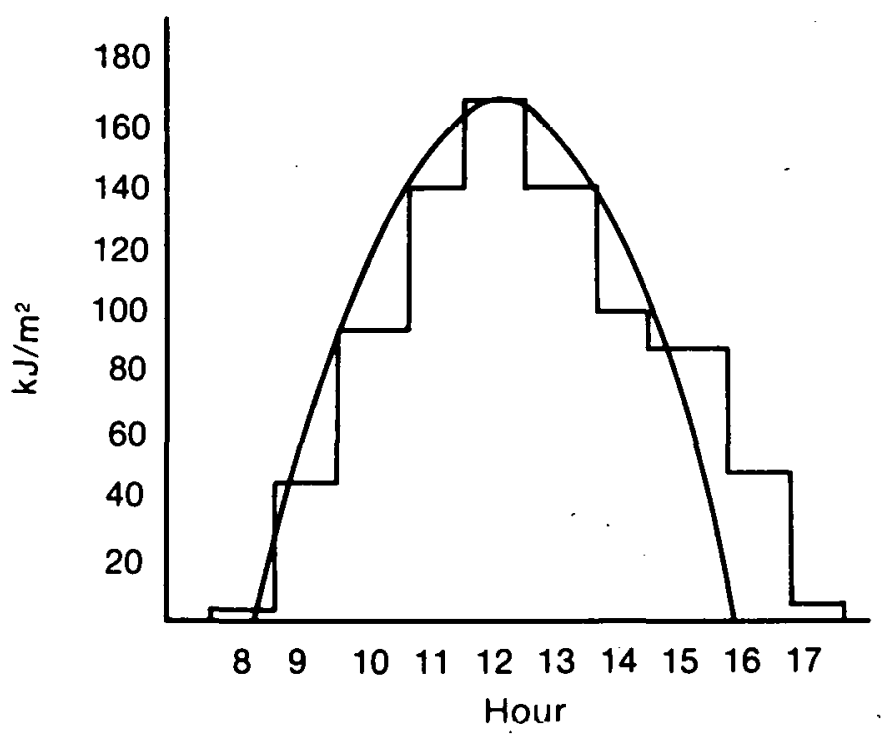

(b)

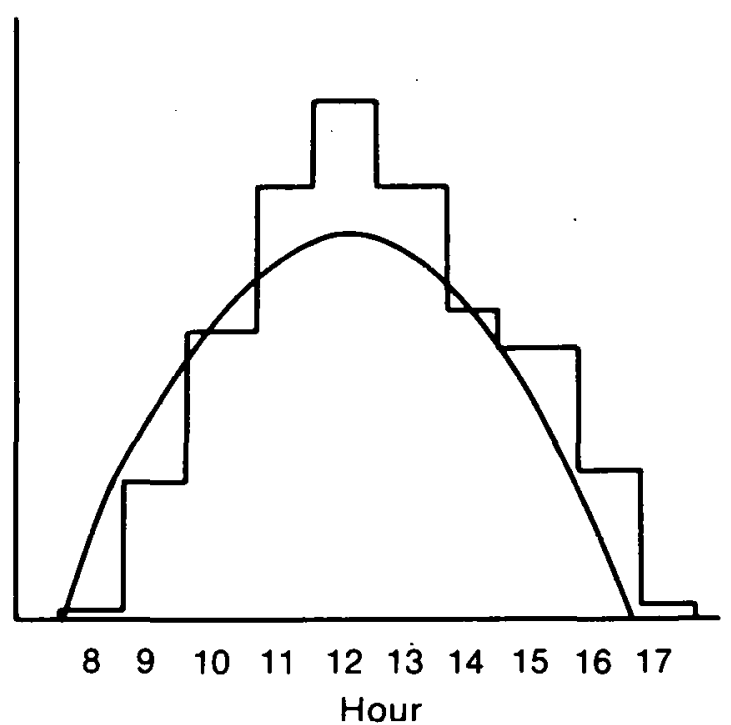

(c)

$$
\begin{gathered}
\text { OMAX }=163 \text { OTOT }=799 \mathrm{~kJ} / \mathrm{m}^{2} \\
\text { IV Cloudy Day }
\end{gathered}
$$

Figure 2-1. Daily Solar Radiation Patterns (concl.) 
Figure 2-1 also provides a contrast between the two sinusoidal models--one based on day length and one based on maximum insolation. The day-length model is the most commonly used, and its usefulness in passive solar modeling has been documented (Barley 1979). However, the day-length model fails to accurately reflect maximum radiation intensity, particularly on partly sunny days. The maximum insolation is important in determining the collector turnon time when collector losses are large. However, the maximum insolation model requires a new plece of dafly radiation data, QMAX, which is not often compiled.

\subsection{SIMULATIONS WITH THE RADIATION MODEL}

The usefulness of the radiation models depends on their accuracy in modeling flat-plate collector performance.

The solar collector equation is (Duffle and Beckman 1974):

$$
Q_{C O L}(t)=F_{r}(\alpha \tau)\left[Q(t)-H_{c}\right]
$$

where $Q_{\mathrm{COL}}(t)=$ instantaneous solar collection,

$F_{r}=$ the collector heat exchange factor,

$(\alpha \tau)=$ the transmission-absorption product,

$Q(t)=$ the instantaneous insolation, and

$\mathrm{H}_{\mathrm{c}}=$ the critical radiation level, determined from collector operating temperature, ambient temperature, and collector heat loss factor.

'lotal solar radiation is the Integral of $Q_{C O L}(t)$ over all time for which $Q(t)$ exceeds $H_{c}$. Since: $F_{r}(\alpha \tau)$ is constant, the collected energy is determined by the integral

$$
Q_{u}=\int\left[\dot{\psi}(\tau)-H_{c}\right] d t
$$

where the integral is taken over all time for which solar collection occurs. This integral will be referred to as the utilizable insolation $\left(\eta_{u}\right)$. Snlar utilization $(\Phi)$ is defined as

$$
\Phi=\frac{Q_{u}}{Q_{t}}
$$

where $Q_{t}$ is total insolation for the given time period. If solar utilization is known, the total solar heat $\left(Q_{c}\right)$ collected for the given period of time may be calculated easily as: 


$$
Q_{c}=F_{r}(\alpha \tau) \Phi A_{c} Q_{t} \quad \text { or } \quad Q_{c}=F_{r}(\alpha \tau) A_{c} Q_{u}
$$

where $A_{c}$ is the collector area.

Dally solar collector performance may be calculated from the hourly data by finding the hourly utilizable insolation:

$$
Q_{u}=\left\{\begin{array}{lll}
Q_{h}-H_{c} & \text { if } & Q_{h}-H_{c}>0 \\
0 & \text { if } & Q_{h}-H_{c}<0
\end{array}\right.
$$

where $Q_{h}$ is hourly insolation. Daily utilization may be found by summing the hourly utilizable insolation and dividing it by the total daily insolation (QTOT).

With the daily radiation model, daily utilizable insolation $\left(Q_{u}\right)$ is found from the integral:

$$
Q_{u}=\int_{t_{a}}^{t_{b}}\left(Q_{k} \cos \omega t-H_{c}\right) d t
$$

with the turn-on and turn-off times set to assure that insolation is greater than $\mathrm{H}_{\mathrm{C}}$, for the period of collector operation. Turn-on and turn-off times were set according to the critical time, $t_{x}$, at which radiation in the model equals $\mathrm{H}_{c}$. This time is given by:

$$
t_{x}=\frac{1}{\omega} \arccos \left(H_{c} / Q_{k}\right) .
$$

where $t=0$ at solar noon.

The calculation based on hourly data introduces uncertainty over the turn-on and turn-off times. Consequently, dally model calculations for purposes of comparison with hourly calculations are performed with the turn-on and turnoff times being one-half hour smaller than the critical time.

The collector equation becomes:

$$
Q_{u}=2 \int_{0}^{t} x^{-1 / 2}\left(Q M A X \cos w t-H_{c}\right) d t .
$$


If $\mathrm{H}_{\mathrm{c}}$ is assumed to be constant, then

$$
Q_{u}=Q T O T \sin \left[\omega\left(t_{x}-1 / 2\right)\right]-2\left(t_{x}-1 / 2\right) H_{c} \text {. }
$$

Utilization is found by dividing the result by QTOT.

Alternatively, the daily radiation model may be used to generate values for hourly insolation. Hourly insolation is found by integration to be:

$$
Q_{h}=Q \operatorname{TOT} \sin \left(\omega t_{h}\right)-\sin \left[\omega\left(t_{h}-1\right)\right]
$$

where $t_{h}$ is the hour, $t_{h}$ at noon being set to zero.* Utilization then may be calculated from hourly insolation in the manner described above. This method yields the same utillzation values as those found by daily integration.

\subsection{VALIDATION}

Accuracy of the dafly radiation models is assessed by comparing utilizations calculated with the daily model to utilization calculated from Typical Meteorological Year weather data. Independent comparisons were made each day of the year in 10 cities for seven different values of the critical level $H_{c}$. The seven values of the critical level were set independently for each day as

$$
\mathrm{H}_{\mathrm{c}}=\operatorname{QMAX}(\mathrm{n} / 8)
$$

where QMAX is the daily maximum insolation and $\mathrm{n}$ is an integer varying from 1 to 7. The critical levels are treated as constants for each day. Thus, for each day considered, seven utilization values are obtained for the seven values of lite irllical level.

Figure 2-2 illustrates how the seven critical levels selected for each day typify all modes of flat-plate collector operation. As shown in Figure 2-2(a), the collector utilization varies from day to day; sunny days typically have high utilization and cloudy days have low or zero utilization. Utilization also is affected by the type of collector; evacuated tube collectors have high utilization values even on cloudy days. Consequently, it is important for the daily radiation models to be proven accurate at both high and low utilization levels. Figure 2-2(b) illustrates the selection of seven values of the critical level to be used in the comparison between the daily models and hourly data. As the figure shows, the different critical levels assure that high and low utilization levels are compared for each day.

Results of the comparisons are tabulated in the following manner. For each critical level, the daily utilizations are averaged over all days having a given percentage of possible sunshine. Model accuracy is determined by how the average utilization values, obtained by using the daily model, compare to the values calculated from hourly data. The root mean square (rms) deviation

\footnotetext{
*An adjustment to this formula must be made at hours near sunrise or sunset to avoid negative values of $\sin \left(\omega t_{h}\right)$.
} 


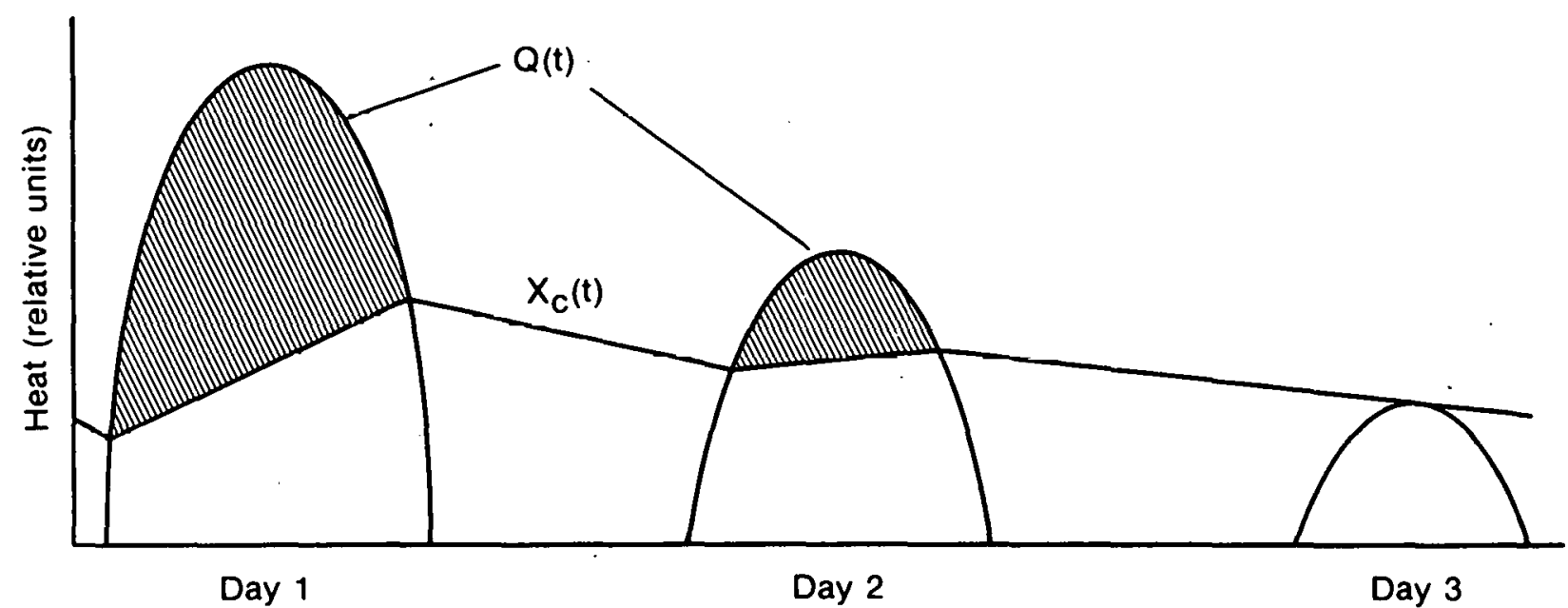

(a) Typical collector operation over a hypothetical three day period. The cross-hatched area gives the utilizable insolation $\left(Q_{u}\right)$ defined by equation 2-4.

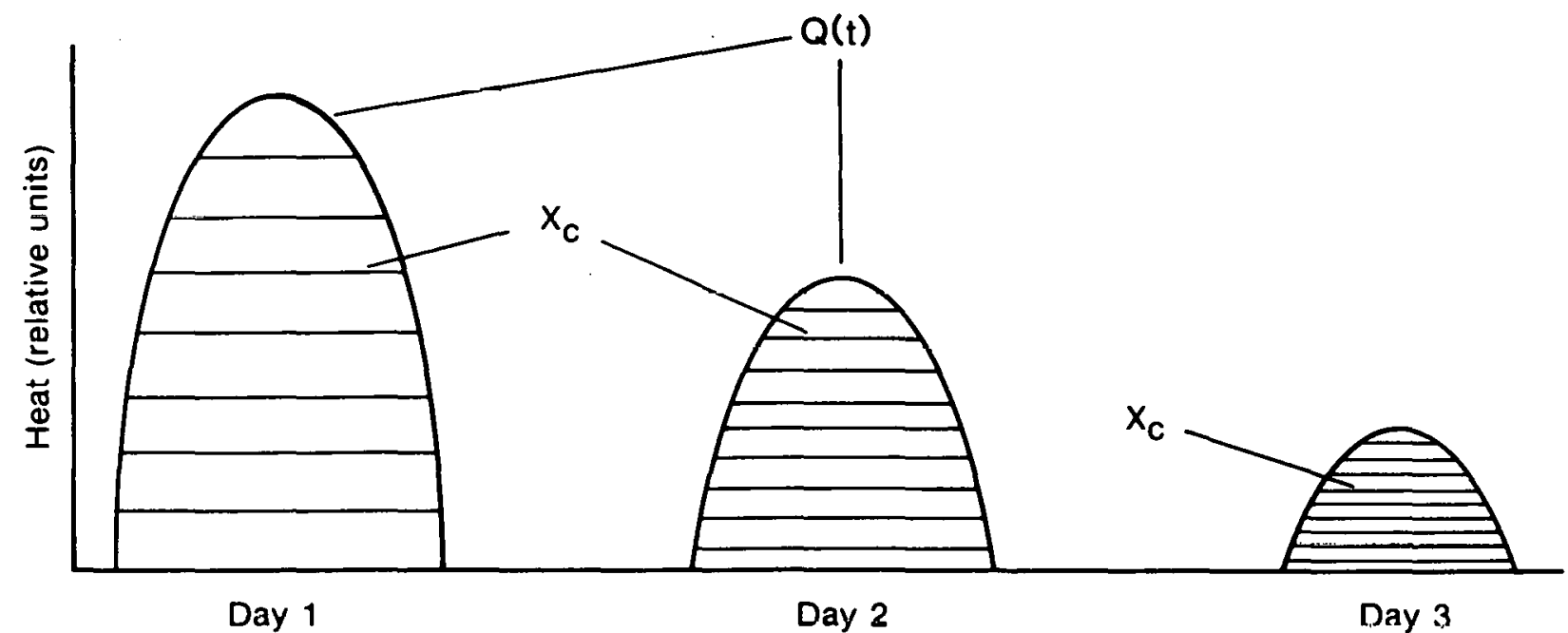

(b) Seven values of the critical level $X_{c}$ for the three days above to be used in testing model accuracy. (See equation 2-7)

Figure 2-2. Illustration of Critical Levels and Solar Utilization 
between the model utilization values and the hourly data values also is calculated. In addition to the tabulation by dally percentage of possible sunshine, the yearly average utilization and standard deviation are calculated, weighted by the daily insolation levels. The yearly average is weighted to assure that the error on days of high insolation counts more than the error on days of low insolation.

When tabulated by percentage of possible sunshine, results were found to be nearly identical for the 10 cities* and uniform throughout the year. Results for Madison, Wis. are presented in Appendix. A. The QMAX model results, shown in Table 1 of Appendix A, show the model to be very accurate for sunny and partly sunny days. On cloudy or partly cloudy days, the QMAX model overest1mates solar collection by $20 \%$ or more. Because cloudy days account for a re1atively small percentage of yearly insolation, the cloudy day errors have a small impact on simulated annual performance. The weighted annual average utilization figures show, at most, a $6 \%$ overestimate of utilization, and often less. The standard deviation, typically 0.05 out of a utilization value of about 0.40 , may be significant.

The results of the day-length mode1, presented in Table 2 of Appendix A, show a different pattern. The day-length model is very accurate for low values of the critical level $\mathrm{H}_{c}$, and 1ncreasingly inaccurate for higher values of $\mathrm{H}_{c}$. This mode1 is also more accurate for sunny days than for cloudy ones, but the weighted yearly average utillzations are low by 15-25\%. Yearly standard deviation ranges up to 0.08 .

The results of Table 2 in Appendix A may be explained by considering the nature of the utilization function. When the critical level is low, the collector is in operation for nearly all the day, and modeling the proper day length is more important than daily maximum insolation when determining collector output. Thus, at low critical levels, the day-length model is more ancurate than the QMAX model. At hipher critical levels, the midday insolation pattern, near the time of maximum insolation, determines collector output. Consequently, the day-length model, which does not accurately model maximum insolation, becomes increasingly inaccurate.

*Albuquerque, N. Mex.; Bismarck, N. Dak.; Boston, Mass.; Caribou, Maine; Dodge City, Kans.; Great Falls, Mont.; Madison, Wis.; Medford, Oreg.; Phoenix, Ariz.; and Santa Maria, Calif. 


\section{SECTION 3.0 \\ MODIFIED DAILY RADIATION MODELS}

In this section, three modifications of the sinusoidal daily radiation models are presented. The modifications have two goals: generate a more accurate model, and eliminate the dependence on hard-to-obtain maximum insolation data.

The possibility of obtaining a more accurate model is indicated by the nature of the error between the daily model and hourly data. Both the utilization values and the model errors are remarkably consistent for the 10 cities when tabulated by daily percentage of possible sunshine.

\subsection{A COMBINED MODEL BASED ON BOTH QMAX $\Lambda$ ND DAY LENGTH}

Results presented in Section 2.0 indicate that the QMAX model yields high utilization values, while the day-length model yields low values. The cause of these errors is the inaccurate estimation of day length in the QMAX model and inaccurate estimation of maximum insolation in the day-length model. By changing the parameters $Q_{k}$ and $\omega$ in equation 2-1, it is possible to generate a sinusoidal function with values for maximum insolation and for day length that are midway between the values of the two previous models.

The combined model is of the same form as the two previous models, with the same basic equation:

$$
Q(t)=Q_{k} \cos (\omega \tau)
$$

In Section 2.0, the two models used the following values of the parameter $Q_{k}$ (from equations 2-2, 2-3, and 2-4):

$$
\begin{aligned}
& \mathrm{Q}_{\mathrm{k}}=\frac{1}{2} \pi \mathrm{QTOT} / \mathrm{t}_{\mathrm{D}} \quad \text { (day-length model) } \\
& \mathrm{Q}_{\mathrm{k}}=\mathrm{QMAX} \cdot \quad(\mathrm{QMAX} \text { model) }
\end{aligned}
$$

In the combined model, the parameter $Q_{k}$ is a linear combination of these two values:

$$
\mathrm{Q}_{\mathrm{k}}=0.6 \mathrm{QMAX}+0.4\left(\frac{1}{2} \pi \mathrm{QTOT} / \mathrm{t}_{\mathrm{D}}\right) \cdot(\text { combined model) }
$$

The frequency $\omega$ is set, as above, to ensure that the daily total insolation matches the actual daily total (QTOT):

$$
\omega=2 Q_{k} / Q T O T \text {. }
$$

Results of the combined mnde1, presented in Table 3 of Appendix A, indicate that it is more accurate than both the day-length and the QMAX model. Average 
utilizations differ from the hourly data values by at most 0.02 , and the annual rms deviations are less than 0.04 . Also, the average utilization shows no tendency to be too high or too low.

\subsection{A MODIFIED MODEL BASED ON MAXIMUM INSOLATION}

A highly accurate daily model can be generated by regarding insolation as the sum of a constant term and a sinusoidal term. The constant term, reflecting perhaps the diffuse component of radiation, is set at $10 \%$ of the daily extraterrestrial radiation or one-half the daily total radiation, whichever is larger. The sinusoidal term is set to reflect maximum insolation. The resulting equations are:

$$
\begin{aligned}
& Q(t)=Q_{\text {con }}+Q_{k} \cos \omega t \\
& Q_{\text {con }}=\operatorname{minimum}\left\{\begin{array}{l}
0.1\left(Q_{x} / t_{D}\right) \\
0.5\left(Q T O T / t_{n}\right)
\end{array}\right. \\
& Q_{k}=Q M A X-Q_{\text {con }} \\
& \omega \quad=2 Q_{k} /\left(Q T O T-Q_{\text {con }} t_{D}\right)
\end{aligned}
$$

where $t_{D}$ is day length and $Q_{X}$ is extraterrestrial radiation. Extraterrestrial radiation may be found monthly from the average daily radiation and the ratio of average dally radiation to extraterrestrial radiation $\left(\mathrm{K}_{\mathrm{T}}\right)$, both commonly available data (Jordan and Liu 1977). Figure 3-1 shows how this representaLlun (referred to below as the modified QMAX model) compares with hourly weather data for the four days presented in Figure 2-1.

The integrated equation for utilization with this model, equivalent to equation $2-13$, is

$$
Q_{u}=\left(Q T O T-Q_{\text {con }} t_{D}\right) \sin \omega\left(t_{x}-\frac{1}{2}\right)+2\left(t_{x}-\frac{1}{2}\right)\left(Q_{c o n}-H_{c}\right) \cdot
$$

Results of the modified QMAX model, presented in Table 4 of Appendix A, are accurate for all but the cloudiest days. The annual average utilizations are all very close to the values calculated from hourly data, within 0.01 , and the largest rms deviation is 0.036 . These results also were duplicated for the other cities used in this study. While further refinements could improve these results, this model demonstrates that a high degree of accuracy is possible when using a daily radiation algorithm. The combined model presented in the previous section may be more useful because it achieves a comparable level of accuracy while being simpler.

\subsection{A MODIFIED MODEL BASED ON DAY LENGTH}

While daily total radiation data are frequently tabulated, daily maximum insolation data are harder to find. Consequently, a modified daily radiation model, not dependent on maximum insolation, will be examined. 

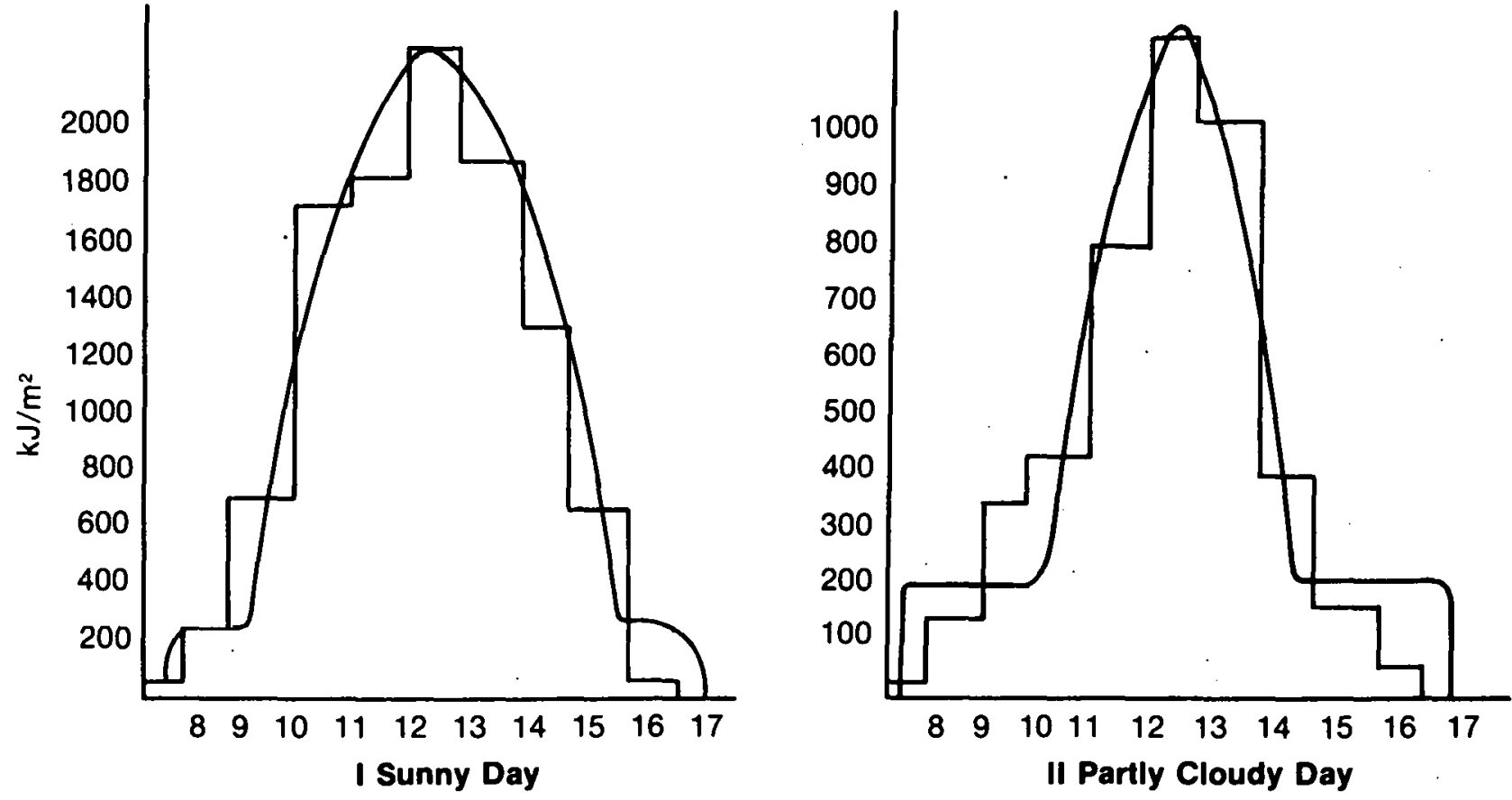

$$
\left.\begin{array}{l}
\text { QM }^{*}=2069 \\
\text { OT }^{*}=8795 \\
\text { DIF }=230 / \text { hour }
\end{array}\right\} \mathrm{kJ} / \mathrm{m}^{2}
$$
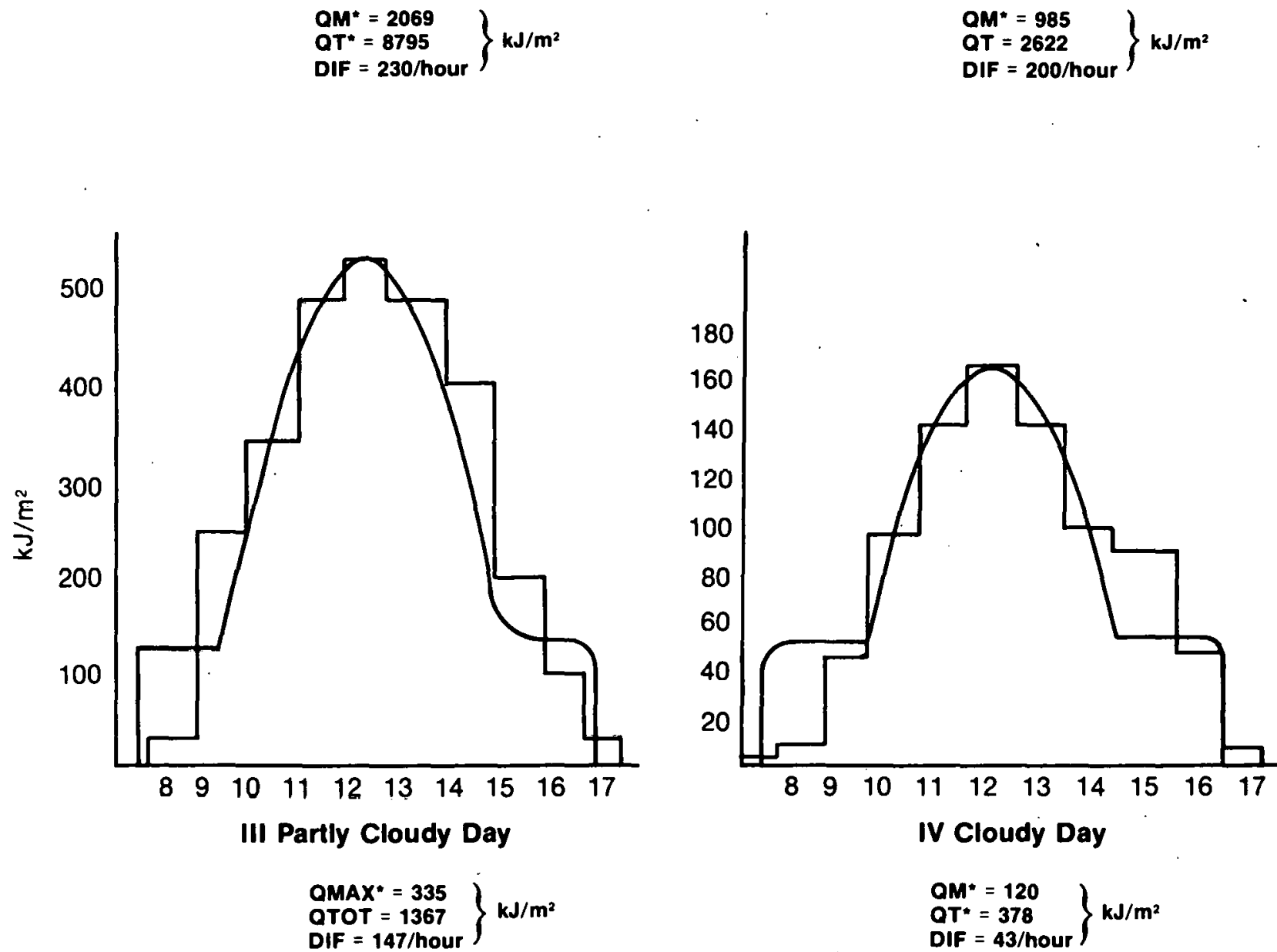

$$
\left.\begin{array}{l}
\text { OM* }=120 \\
\text { OT" }=378 \\
\text { DIF }=43 / \text { hour }
\end{array}\right\} \mathrm{kJ} / \mathrm{m}^{2}
$$

Figure 3-1. Daily Solar Radiation Patterns, From Modifled Model

Daily insolation pattern calculated by the second daily model for four days. The superimposed hourly pattern is from the " $b$ " graphs in Figure 2-1. 


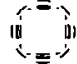

As already noted, the day-length model is inaccurate because it generally underestimates maximum insolation. The discrepancy between the parameter $Q_{k}$ calculated by equations 2-2 and $2-3$ and the actual maximum insolation (QMAX) indicates a strong correlation to cloud cover. On cloudy days in Madison, Wis., this discrepancy averages $30 \%$, while on sunny days the discrepancy is only $3 \%$. The discrepancy also shows a consistently increasing trend as daily percentage of possible sunshine decreases. Insolation for Albuquerque, N. Mex., shows a similar pattern but the cloudy day discrepancy is only $21 \%$.

The modified day-length model presented here begins with the same form:

$$
Q(t)=Q_{k} \cos \omega t \text {. }
$$

The parameter $Q_{k}$ is calculated based on day length and then increased by a factor which is a function of percentage of possible sunshine. The equations become:

$$
\begin{aligned}
& Q_{k}=I_{r}\left(\frac{1}{2} \operatorname{QTOT} / t_{D}\right) \\
& I_{r}=1+0.25\left(1-Q T O T / Q_{x}\right)
\end{aligned}
$$

where $Q_{x}$ is the daily extraterrestrial radiation. The fraction $Q T O T / Q_{x}$ is the daily percentage of possible sunshine, varying from 0 to 1 . As before, the parameter $\omega$ is calculated to make total radiation equal to the actual total:

$$
\omega=2 \mathrm{Q}_{\mathrm{k}} / \mathrm{QTOT}
$$

Results from this model are presented in Table 5 of Appendix A. The annual average utilizations are all accurate to within $2 \%$. However, the breakdown of the data by percentage of possible sunshine shows significant errors, most notable for $30-40 \%$ days. The annual rms deviations reach a maximum of 0.063. These results suggest that this model could be useful. A more thnrough analysis to find the best values for the factor $I_{c}$ should improve accuracy. 


\section{SECTION 4.0 \\ RESULTS OF DAILY SIMULATIONS}

The most direct way of estimating model accuracy is to simulate a known system and compare results. In this section, daily simulation results will be presented for three types of systems that have been the subject of more detailed study. The three comparisons that will be made are (1) a simulated active solar heating system with daily storage, to be compared with $\mathrm{f}$-chart, (2) annual storage solar heating system compared with hourly simulations with the SOLANSIM computer code, and (3) a "two-tank" solar heating system with both a daily and a seasonal storage tank, compared to the original designs of Cha, Conner, and Mueller (1979).

Simulation of an active solar heating system with dally storage in Madison, Wis., was performed using hourly steps with hourly insolation data generated by the daily radiation models. Then, the same simulation was performed using hourly Typical Meteorological Year weather data. Figure 4-1 shows how the simulation with each of the daily radiation models compares to simulation with hourly weather data, for flat-plate collectors.

The QMAX model and the combined mode1 simulations are the most accurate, with results consistently within $1.5 \%$ of the hourly data results. These models performed as well or better in simulations with evacuated tube collectors and in different locations. The day-length model is inaccurate, consistently underestimating system performance by $5 \%$. The modified day length mode1, while not as accurate as the models based on QMAX, is still of sufficient accuracy to be useful. It consistently overestimates system performance, but only by $2-3 \%$.

Simulations also. were performed in Madison for an evacuated tube collector, and in Albuquerque, N. Mex., for both flat-plate and evacuated tube collectors. In each of these cases, performance of the day-length model improved significantly, underestimating performance by only $2 \%$. The improved performance indicates that the day-length model may be useful in sunny locations or in systems with high utilization factors.

Figure 4-1 also shows the results of a simulation that used daily, rather than hourly, steps with the QMAX model. This simulation is accurate for systems supplying a large fraction of solar heat, but it decreases in accuracy for smaller systems. The inaccuracy introduced by the use of daily steps is, at most, 5\% for flat-plate collector systems. For evacuated tube collector systems, the daily step more1, was accurate to within $1 \%$.

A comparison is made in Figure 4-2 between the hourly simulation using hourly weather data and results from f-chart. This comparison shows significant discrepancies between the simulation and f-chart, occasionally as high as $5 \%$. The discrepancies indicate that differing assumptions about system performance have a greater impact on results than inaccuracies in the daily radiation algorithm. 
Model with hourly data

Daily radiation model with hourly steps

- Daily radiation model with daily steps

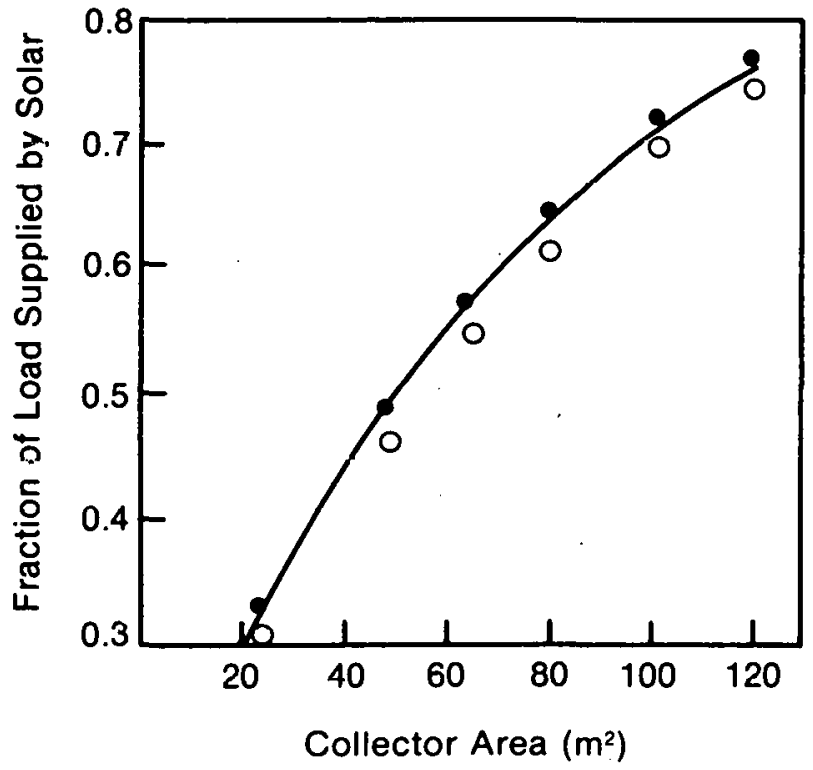

(a). The QMAX Model

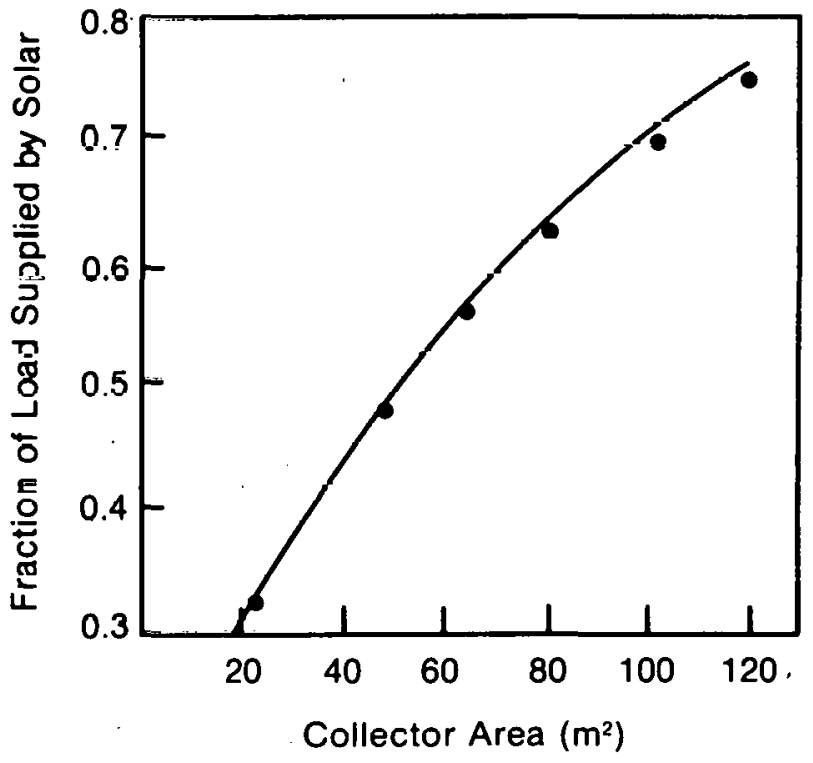

(c) The Modified QMAX Model

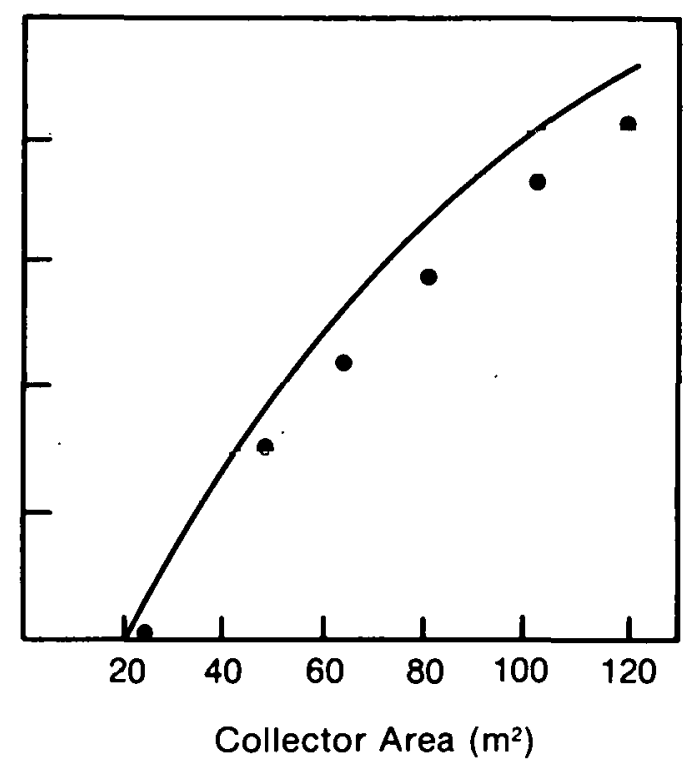

(b) The Day Length Model

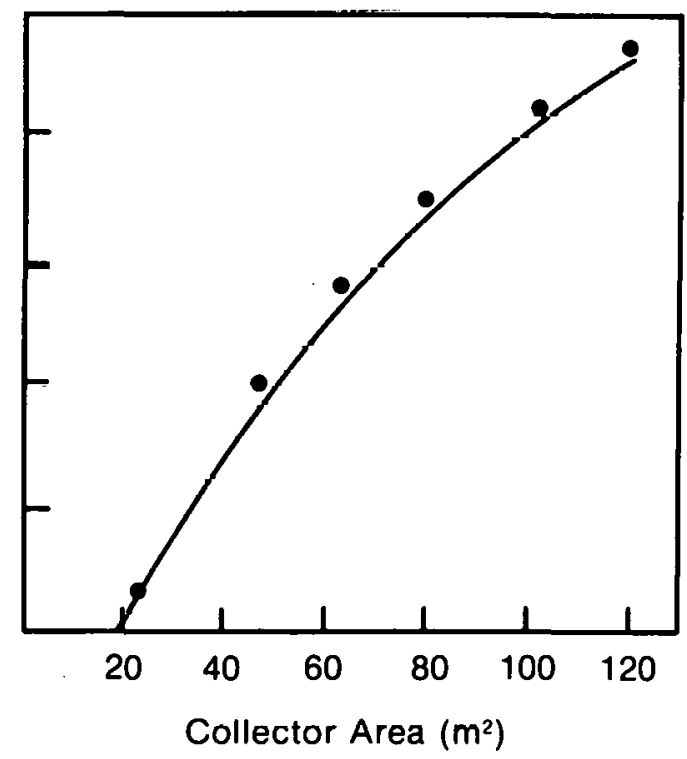

(d) The Modified Day Length Model

Figure 4-1. Results of Solar Heating System Simulations

Comparison of simulations using daily radiation models (discrete points) simulations using hourly weather data (solid lines), Flat-plate collector system, Madison, Wisconsin 


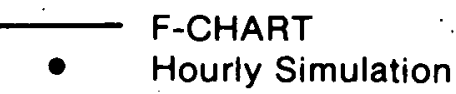

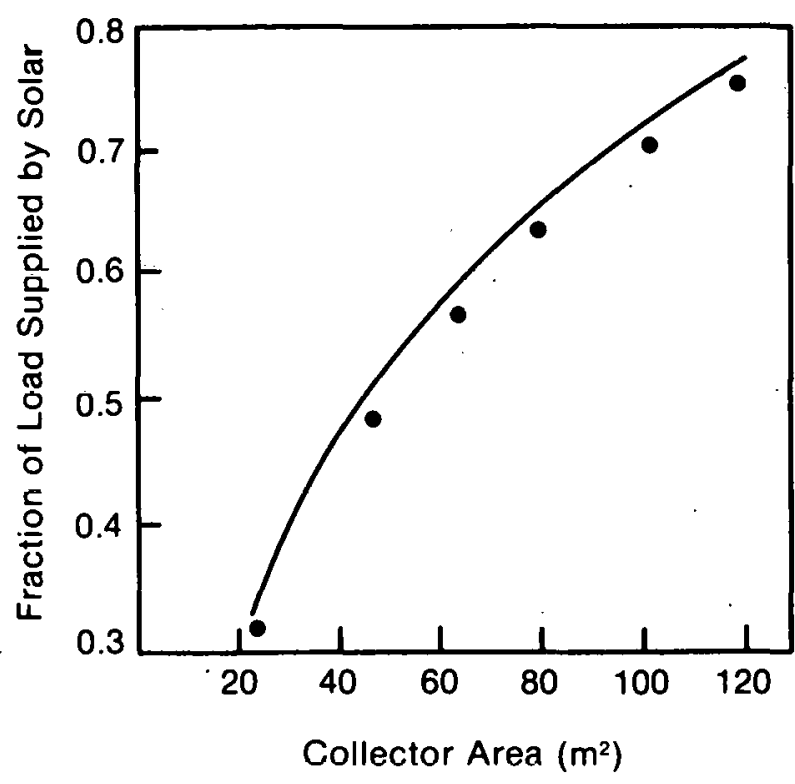

(a) Flat-Plate Collector Madison, Wis.

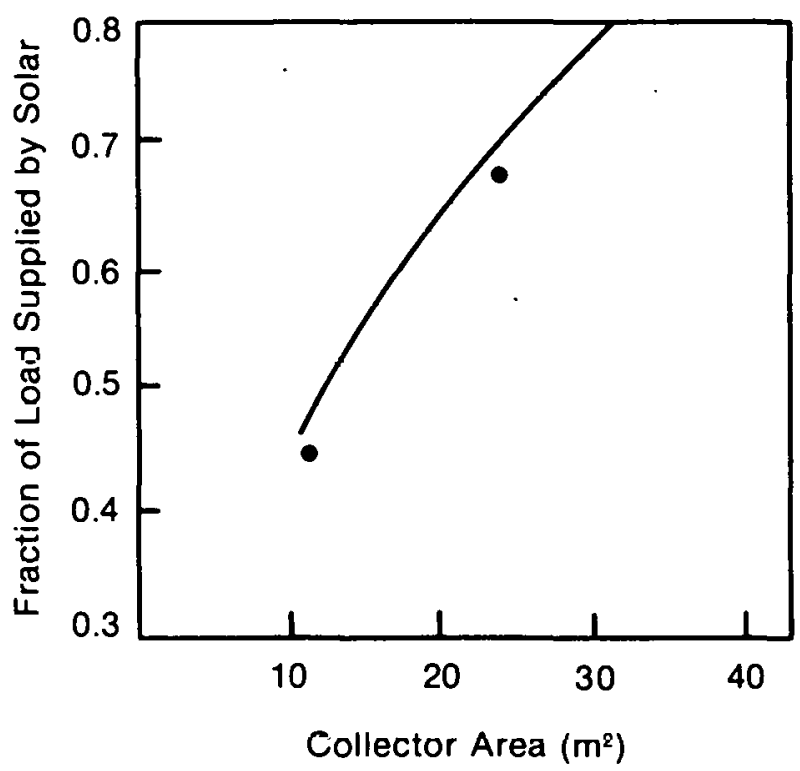

(c) Flat-Plate Collector Albuquerque, N.M.

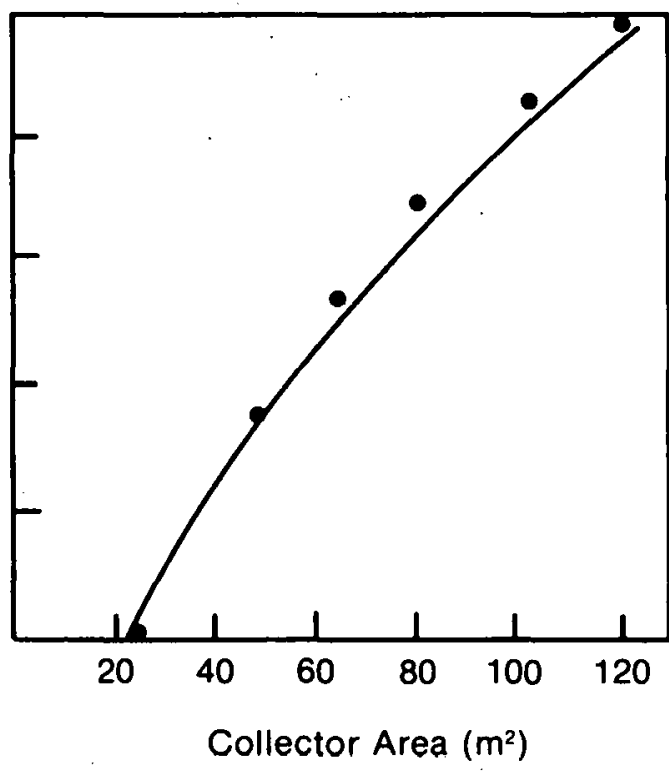

(b) Evacuated Tube Collector Madison, Wis.

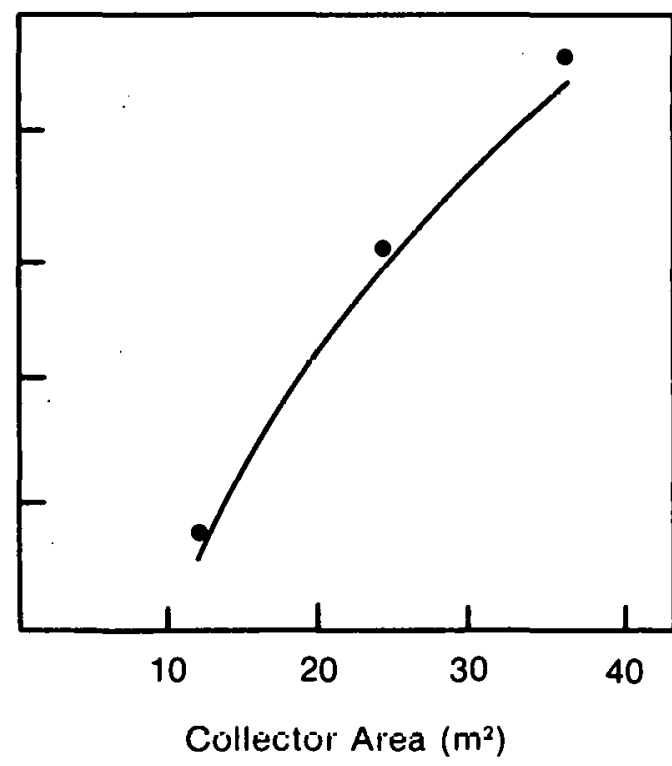

(d) Evaluated Tube Collector Albuquerque, N.M.

Figure 4-2. Comparison of Simulation Results from Figure 4-1 with F-CHART 
Simulations of annual storage systems were performed with the dally radiation models, using daily steps, and compared to a detalled study of annual storage systems based on the SOLANSIM computer code (Baylin et al. 1980). In the study with SOLANSIM, the yearly swing in storage temperature is calculated, assuming that the system provides $100 \%$ of the space heating load so long as the storage temperature remains above $33^{\circ} \mathrm{C}$. The key parameter in the comparison is, therefore, the end-of-year storage temperature. Results of the comparison, performed for all 10 cities, are as follows.

- The QMAX model yields the most accurate results. For flat-plate co1lectors, the calculated end-of-year storage temperatures are consistently within $1^{\circ} \mathrm{C}$ of the SOLANSIM results. For evacuated tube collectors, the calculated temperatures are consistently higher than the SOLANSIM results, but the discrepancy is always less than $2^{\circ} \mathrm{C}$.

- The day-length model yields consistently low results for flat-plate collectorg. The discrepancy between the calculated end of wyedi teruperature and the SOLANSIM results is approximately $4^{\circ} \mathrm{C}$, which in these systems is equivalent to $5 \%$ of the annual heat load. In contrast with the results of the $f$-chart comparison, this error persisted in sunny locations such as Albuquerque, N. Mex. For evacuated tube collectors, the day-length model again underestimated performance, but this time results were within $1.5^{\circ} \mathrm{C}$ of the SOLANSIM results. For evacuated tube collectors, this model is of sufficient accuracy to be used.

- According to the analysis presented in Sections 2.0 and 3.0 , the combined model presented in Section 3.1 should be the most accurate daily radiation model. In the comparison with SOLANSIM, the combined model yields very accurate results for evacuated tube collectors, with calculated storage temperatures consistently within $1^{\circ} \mathrm{C}$ of the SOLANSIM results. For flat-plate collectors, the combined model underestimates system performance with end-of-year temperatures $2^{\circ} \mathrm{C}$ too low.

- The modified day-length model presented in section 3.3 consistently yields final temperatures about $2^{\circ} \mathrm{C}$ above the SOLANSIM results for both flat-plate collectors and evacuated tube collectors.

Lastly, the QMAX model was used to simulate the performance of the "two-tank" system designed by Cha, Conner, and Mueller (1979). In this system, a solar collector operated with two storage tanks, one sized for storage on a daily basis and the other an annual storage tank. The collector operates to charge whichever tank is at the lower temperature, thus assuring the most efficlent operation. Heat for the building load is drawn preferentially from the daily storage tank. The advantage of the two-tank system over single-tank annual storage lies in the efficient collection of low temperature solar heat during the early winter, when the fully charged annual storage tank is too hot to permit efficient collection.

A simulation for the two-tank system was constructed by using daily simulation intervals and the QMAX daily model. Figure 4-3 compares the simulation results with the designs of Cha, Conner, and Mueller (1979). The QMAX model results in virtually identical designs. 


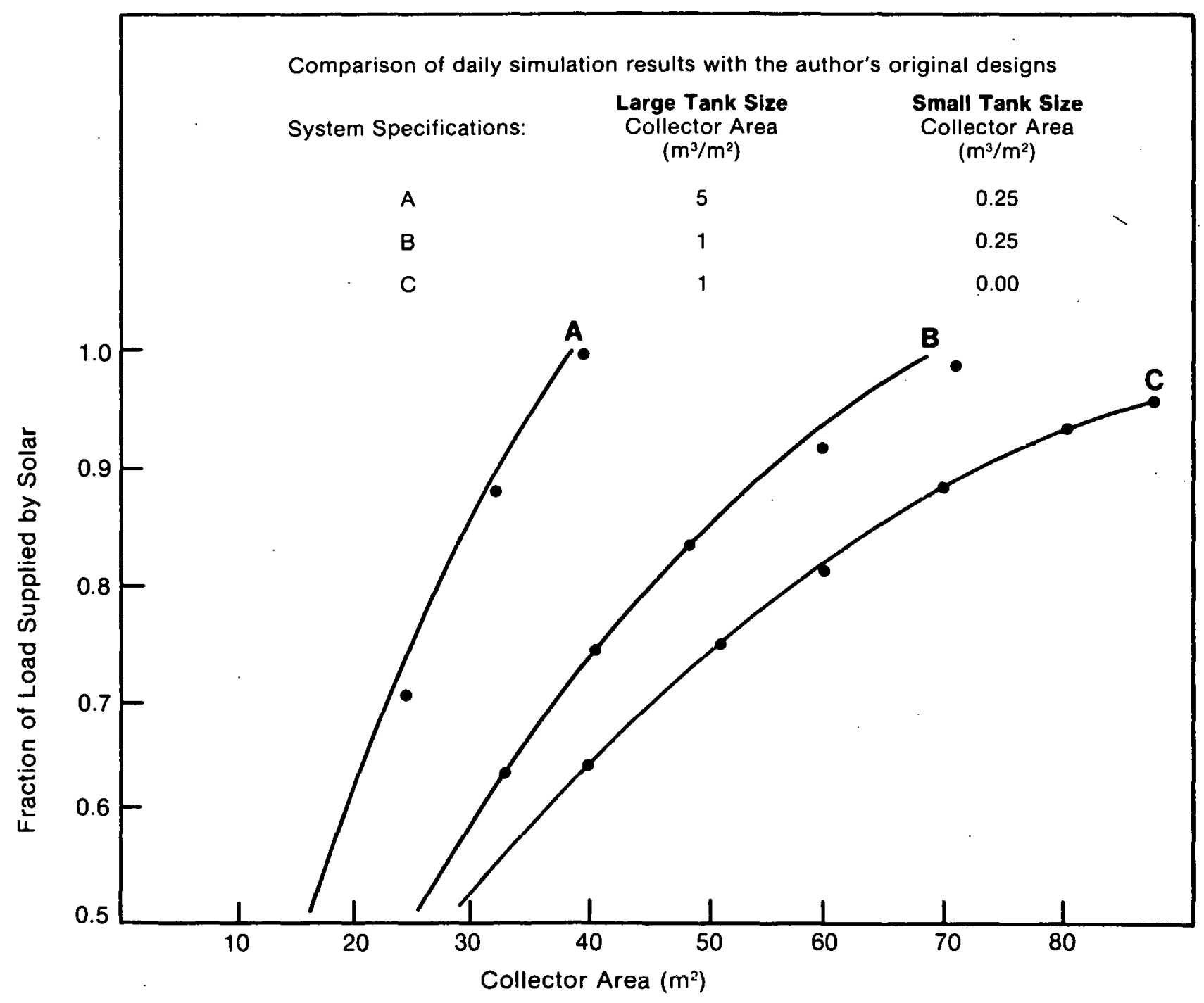

Figure 4-3. Design for Two-Tank System 
SEPI㭗 
SECTION 5.0

CONCLUSION

The results of this study show that dafly radiation algorithms are accurate for use in solar system design, with errors 1 imited to $2 \%$. By contrast, differing assumptions about system performance can cause design errors of greater significance.

The accuracy of the daily radiation models is particularly impressive when the inaccuracies of existing radiation data, or the inherent variability of weather, are taken into account. The discrepancy between anisotropic (Hay 1979) and isotropic (Klein 1978) algorithms for calculating radiation on tilted surfaces, alone, amounts to $10 \%$.

The following are specific conclusions and recommendations of this study.

- The QMAX sinusoidal function yields the most accurate results of the daily radiation models presented here.

- The day-length model is the most commonly used daily radiation algorithm. Although it yields accurate results for evacuated tube collectors, the model consistently results in design errors of $5 \%$ for flatplate collectors. All of the modified daily models presented here are more accurate.

- Use of daily maximum insolation data permits significantly greater accuracy in a dally radiation model. Consequently, more of an effort should be made to collect and tabulate such data.

- If maximum daily insolation data are unavailable, the modified daylength model is of sufficient accuracy to be useful to designers. Also, it is likely that this model's accuracy could be improved by further study.

- Use of daily radiation algorithms for solar heating design could be particularly useful to designers with access to minicomputers. To facilitate this use, more of an effort should be made to tabulate insolation and temperature data on a daily basis rather than on an hourly basis. Formulas for generating the total and maximum daily insolation on a tilted surface directly from horizontal data also need to be developed. 


\section{Sइㅋㄴ}


SECTION 6.0

REFERENCES

Barley, C. D. 1979. "Passive Solar Modeling with Daily Weather Data." Proceedings of the Fourth National Passive Solar Conference. Kansas City, MO; 3-5 October 1979.

Baylin, F.; Monte, R.; Sillman, S. 1980. Annual Cycle Thermal Energy Storage for a Community Solar System: Details of Sensitivity Analysis. Golden, CO: Solar Energy Research Institute; SERI/TR-355-575.

Baylin, F; Sillman, S. 1980. Systems Analysis Techniques for Annual-Cycle Thermal Energy Storage Systems. Golden, CO: Solar Fnergy Research Institute; SERI/RR-721-676.

Cha, R. K.; Conner, D. W.; Mueller, R. 0. 1979. "A Two-Tank Seasonal Storage Concept for Solar Space Heating of Buildings." Proceedings of Second Miami International Conference on Alternative Energy Sources. Miami, FL; 10-13 December 1979.

Duffie, W.; Beckman, R. 1974. Solar Energy Thermal Processes. Wiley and Sons.

Hay, J. E. 1979. "Calculation of Monthly Mean Solar Radiation for Horizonta1 and Inclined Surfaces." Solar Energy. Vol. 23 (No. 4): 1979; p. 301.

Jordon, R. C.; Liu, B. Y.; editors. 1977. Application of Solar Energy for Heating and Cooling of Buildings. New York: American Society of Heating, Refrigeration, and Alr Conditioning Engineers.

Klein, S. A. 1978. "Calculation of Flat-Plate Collector Utilizability." Solar Energy. Vol. 21 (No. 5): 1978; p. 393. 


\section{SER1}


Appendix A

COT.LF.CTOR UTILIZATION FOR VARYING $\mathrm{H}_{\mathrm{C}}$ LEVELS, TYPICAL METEOROLOGICAL YEAR, MADISON, WIS.

Five Tables 
Table A-1. COLLECTOR UTILIZATION FOR VARYING H LEVELS TYPICAL METEOROLOGICAL YEAR, MADISON, WIS. THE QMAX MODEL

\begin{tabular}{|c|c|c|c|c|c|c|c|}
\hline \multirow[b]{3}{*}{ PPS } & \multirow[b]{3}{*}{ ND } & \multicolumn{2}{|c|}{ Utillzations } & \multirow{2}{*}{\multicolumn{2}{|c|}{$0.25 * 0 \mathrm{M}$}} & \multirow{2}{*}{\multicolumn{2}{|c|}{$0.375 * Q M$}} \\
\hline & & $\mathrm{H}_{C}=\ldots$ & $125 * Q M$ & & & & \\
\hline & & $\mathbf{H}$ & D & H & D & $\mathbf{H}$ & D \\
\hline $\begin{array}{cc}0.0- & .1 \\
.1- & .2 \\
.2- & .3 \\
.3- & .4 \\
.4- & .5 \\
.5- & .6 \\
.6- & .7 \\
.7- & .8 \\
.8- & .9 \\
.9-1.0 \\
\text { ANNUAL* }\end{array}$ & $\begin{array}{r}35 \\
36 \\
28 \\
38 \\
34 \\
53 \\
73 \\
47 \\
19 \\
2 \\
365\end{array}$ & $\begin{array}{l}.7527 \\
.7200 \\
.7437 \\
.7321 \\
.7553 \\
.7781 \\
.7878 \\
.7998 \\
.8133 \\
.8314 \\
.7798\end{array}$ & $\begin{array}{l}.7856 \\
.7841 \\
.7896 \\
.7871 \\
.7932 \\
.7967 \\
.8004 \\
.7998 \\
.8005 \\
.8033 \\
.7977\end{array}$ & $\begin{array}{l}.5526 \\
.5112 \\
.5392 \\
.5321 \\
.5646 \\
.5978 \\
.6123 \\
.6296 \\
.6399 \\
.6698 \\
.5989\end{array}$ & $\begin{array}{l}.6138 \\
.6124 \\
.6176 \\
.6152 \\
.6211 \\
.6244 \\
.6279 \\
.6274 \\
.6281 \\
.6308 \\
.6254\end{array}$ & $\begin{array}{l}.3916 \\
.3475 \\
.3785 \\
.3767 \\
.4050 \\
.4402 \\
.4575 \\
.4767 \\
.4875 \\
.5171 \\
.4429\end{array}$ & $\begin{array}{l}.4585 \\
.4572 \\
.4622 \\
.4598 \\
.4654 \\
.4685 \\
.4719 \\
.4714 \\
.4720 \\
.4746 \\
.4695\end{array}$ \\
\hline
\end{tabular}

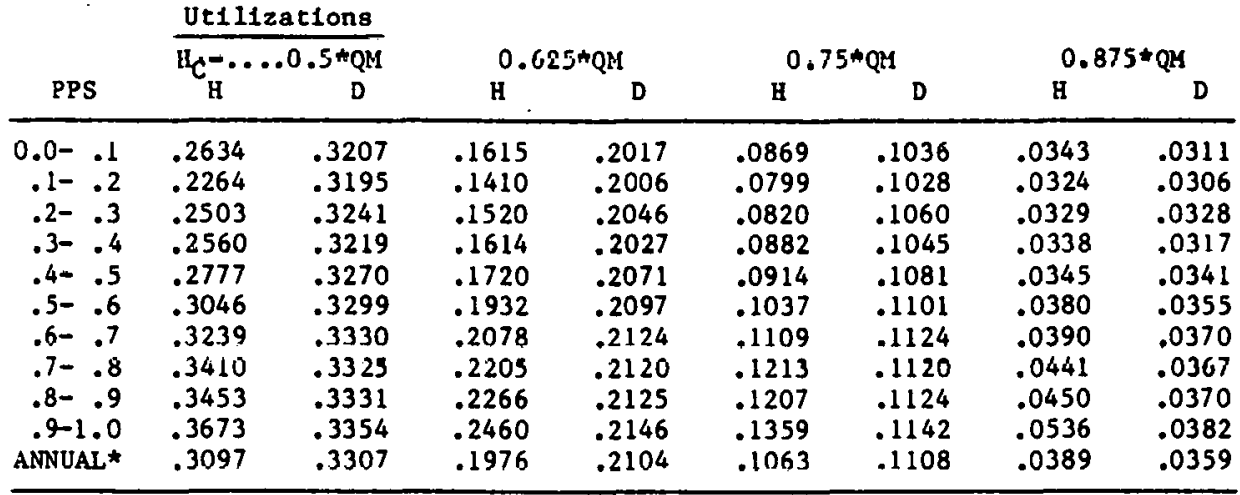

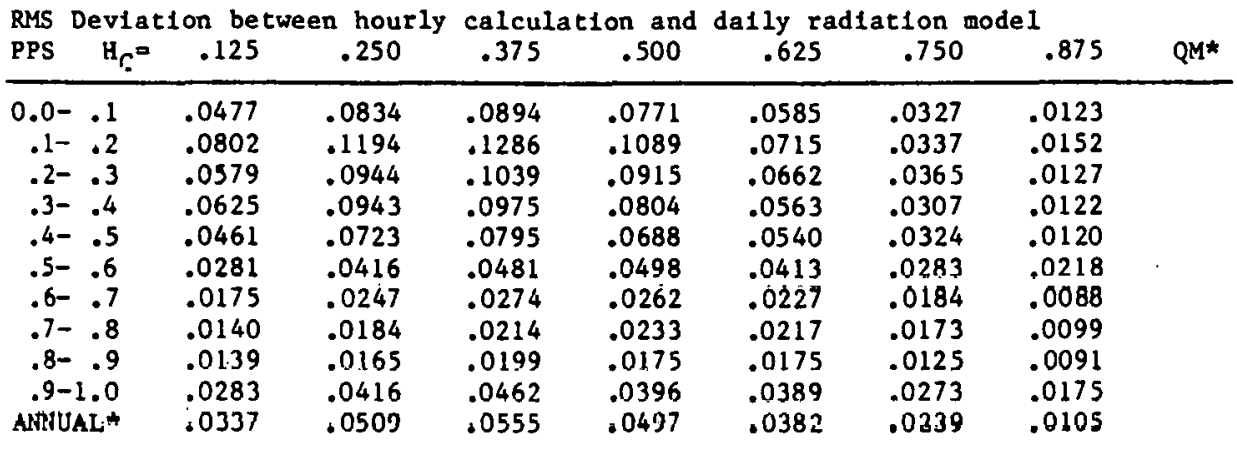

PPS = Daily percent of possible sunshine

$\mathrm{ND}=$ Number of days with given PPS

${ }_{C}=$ Critical radiation level set each day as a fixed percentage of $Q M$, the dally maximur insolation

H = Hourly calculation

$D=$ Daily radiation model

ANNUAL * Yearly average utilization and RMS deviation weighted by dally total insolation. 
Table A-2. COLLECTOR UTILIZATION FOR VARYING HC LEVELS TYPICAL METEOROLOGICAL YEAR, MADISON, WIS. DAY LENGTH MODEL

\begin{tabular}{|c|c|c|c|c|c|c|c|}
\hline \multirow[b]{3}{*}{ PPS } & \multirow[b]{3}{*}{ ND } & \multicolumn{2}{|c|}{ Ut1lizations } & \multirow{2}{*}{\multicolumn{2}{|c|}{$0.25 \star^{*} Q M$}} & \multirow{2}{*}{\multicolumn{2}{|c|}{$0.375 * a$}} \\
\hline & & $\mathrm{H}_{C}=$. & $.125 * Q M$ & & & & \\
\hline & & & D & H & D & $\mathrm{H}$ & $D$ \\
\hline $\begin{array}{rr}0.0- & .1 \\
.1- & .2 \\
.2- & .3 \\
.3- & .4 \\
.4- & .5 \\
.5- & .6 \\
.6- & .7 \\
.7- & .8 \\
.8- & .9 \\
.9-1.0 \\
\text { ANNUAL }\end{array}$ & $\begin{array}{r}35 \\
36 \\
28 \\
38 \\
34 \\
53 \\
73 \\
47 \\
19 \\
2 \\
365\end{array}$ & $\begin{array}{l}.7527 \\
.7200 \\
.7437 \\
.7321 \\
.7553 \\
.7781 \\
.7878 \\
.7998 \\
.8133 \\
.8314 \\
.7798\end{array}$ & $\begin{array}{l}.7344 \\
.7078 \\
.7346 \\
.7146 \\
.7472 \\
.7669 \\
.7865 \\
.7925 \\
.7994 \\
.8319 \\
.7737\end{array}$ & $\begin{array}{l}.5526 \\
.5112 \\
.5392 \\
.5321 \\
.5646 \\
.5978 \\
.6123 \\
.6296 \\
.6399 \\
.6698 \\
.5989\end{array}$ & $\begin{array}{l}.5136 \\
.4682 \\
.5122 \\
.4773 \\
.5328 \\
.5672 \\
.6014 \\
.6134 \\
.6261 \\
.6878 \\
.5795\end{array}$ & $\begin{array}{l}.3916 \\
.3475 \\
.3785 \\
.3767 \\
.4050 \\
.4402 \\
.4575 \\
.4767 \\
.4875 \\
.5171 \\
.4429\end{array}$ & $\begin{array}{l}.3265 \\
.2763 \\
.3247 \\
.2805 \\
.3480 \\
.3915 \\
.4360 \\
.4523 \\
.4694 \\
.5530 \\
.4088\end{array}$ \\
\hline
\end{tabular}

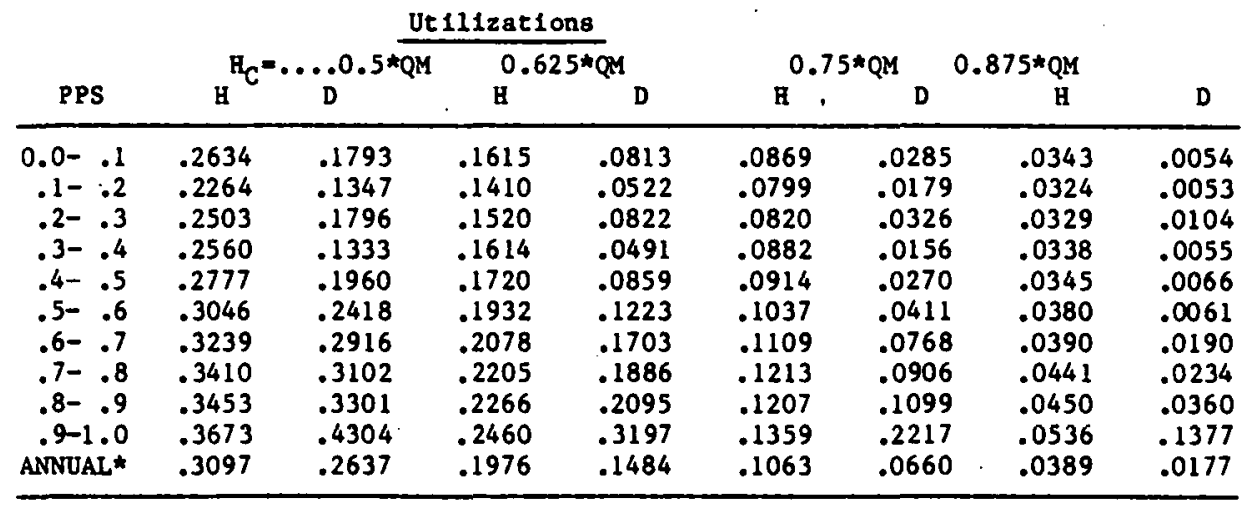

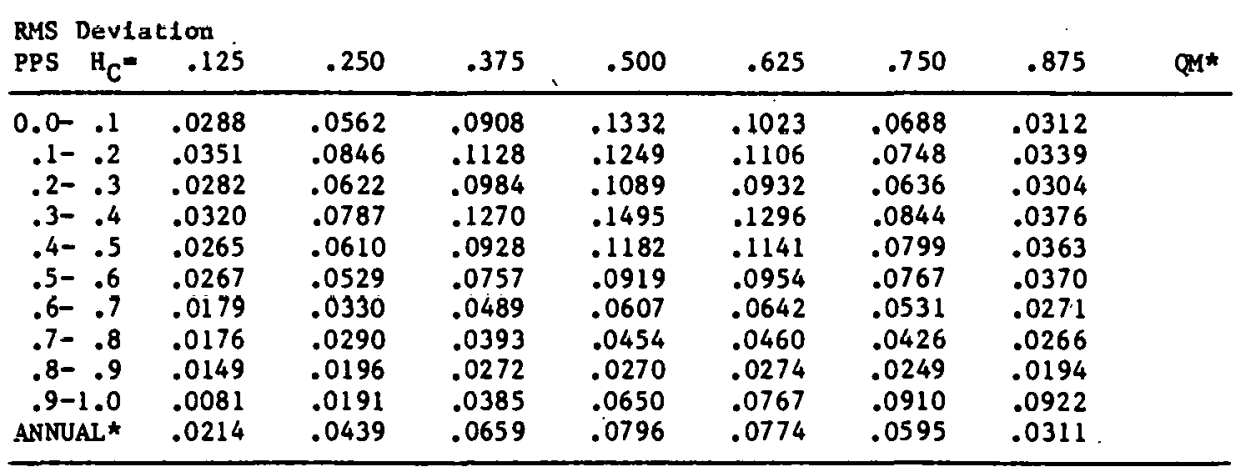

PPS = Dafly percent of possible sunshine

ND = Number of days with given PPS

$t_{C}=$ Critical radiation level set each day as a flxed percentage of $M$, the dally maximum insolation

$H=$ Hmurly calculation

D = Dally radiation model

ANNUAL* - Yearly average utflization and RMS deviation welghted by dally total Insolation. 
Table A-3. COLLECTOR UTILIZATION FOR VARYING HC LEVELS TYPICAL METEOROLOGICAL YEAR, MADISON, WIS. COMBINED MODEL

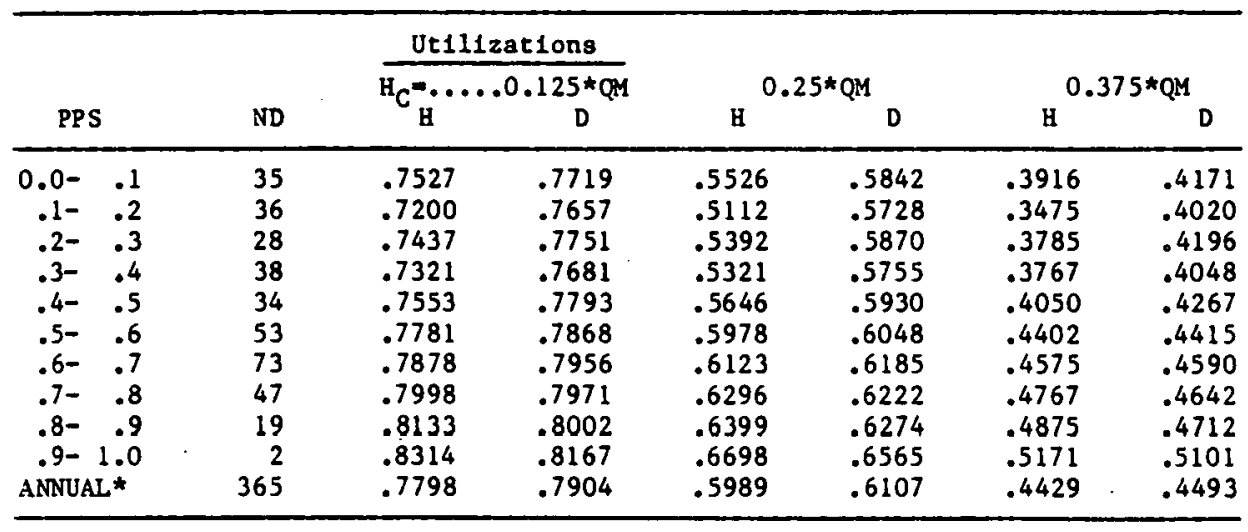

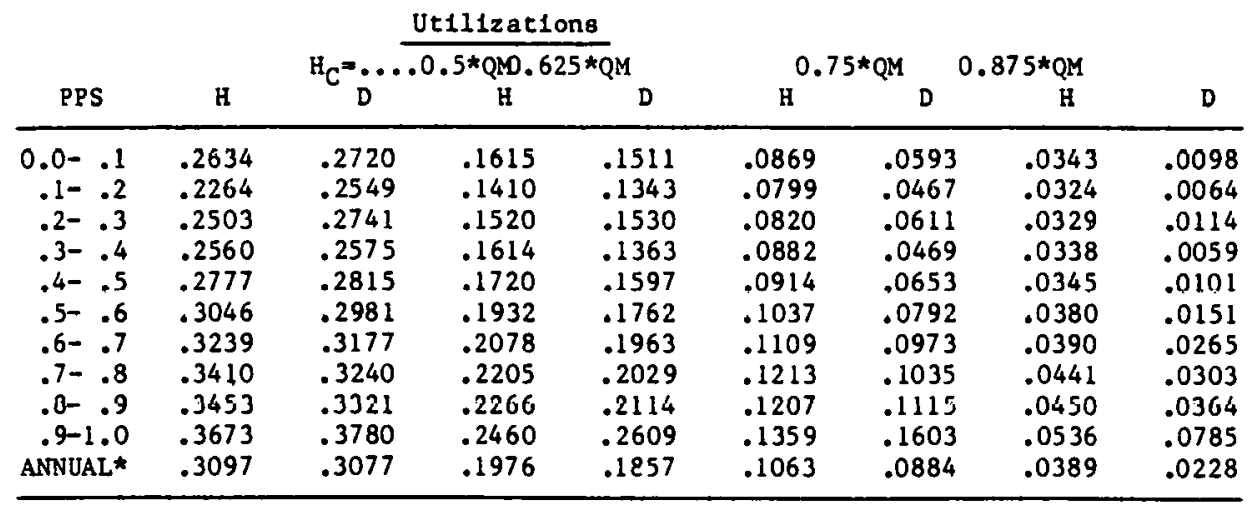

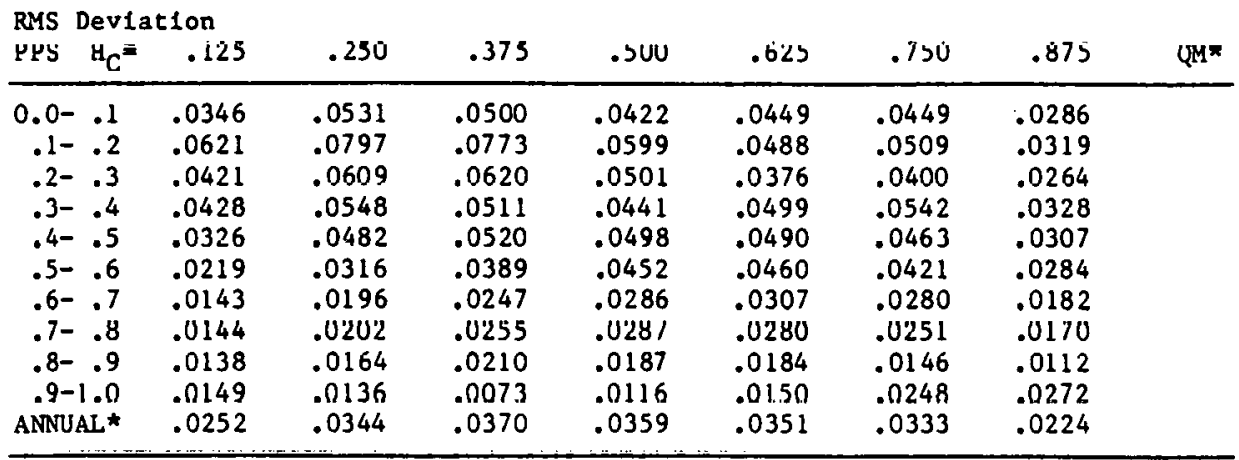

PPS = Dally percent of possible sunshine

ND $=$ Number of days with given PPS

$H_{C}=$ Critical radiation level set each day as a fixed percentage of $Q M$, the dally maximum insolacion

$H=$ llourly calculation

$D=$ Dally radiation model

ANNUAL* = Yearly average utilization and RMS deviation weighted by dally total Insolation. 
11:

Table A-4. COLLBCTOR UTILIZATION FOR VARYING H LEVELS TYPICAL METEOROLOGICAL YEAR, MADISON, WIS. THE MODIFIED OMAX MODEL

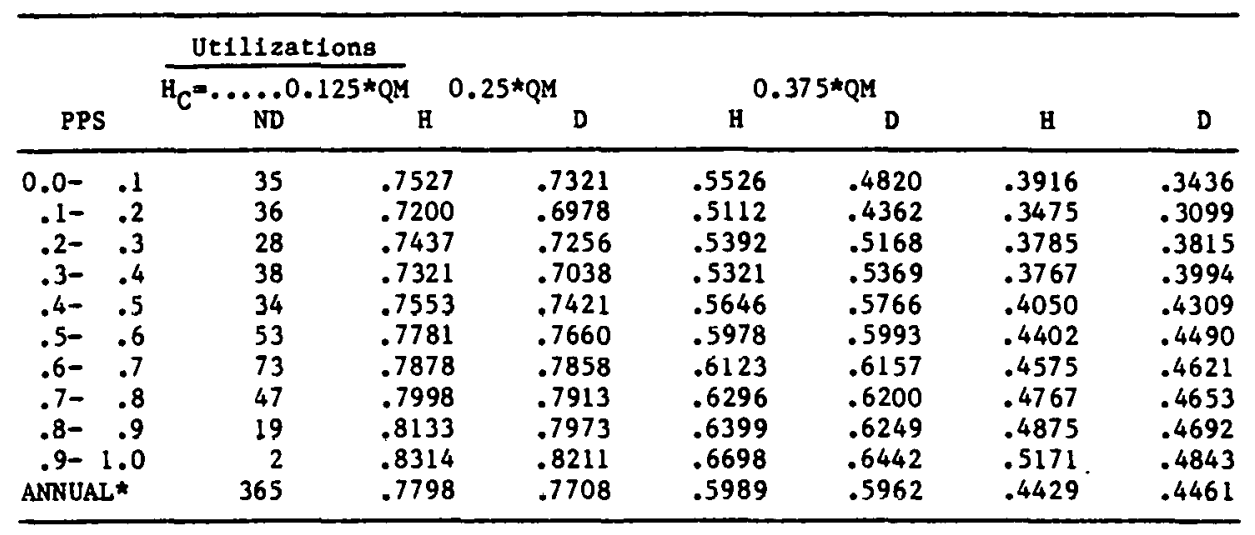

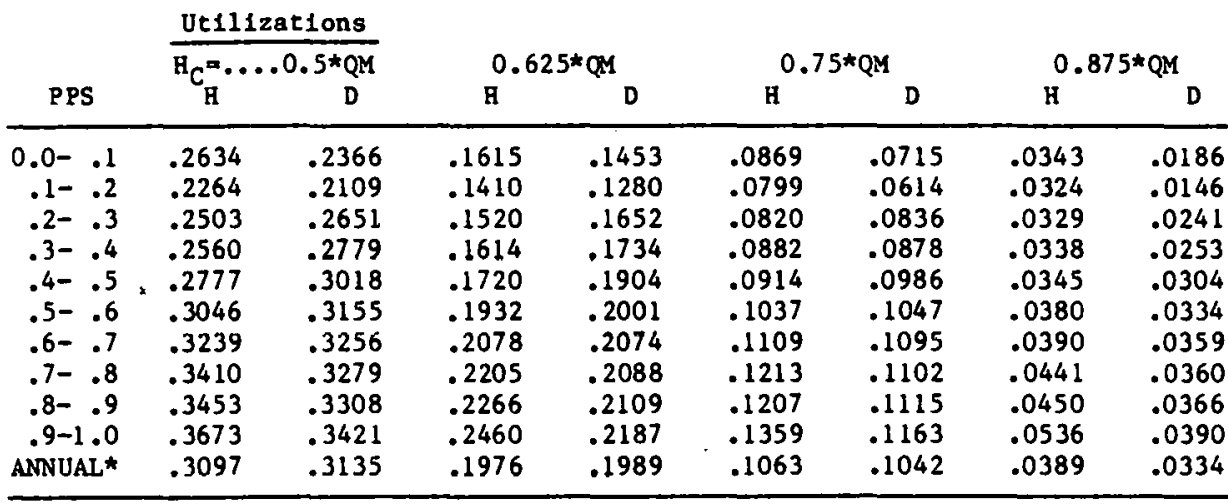

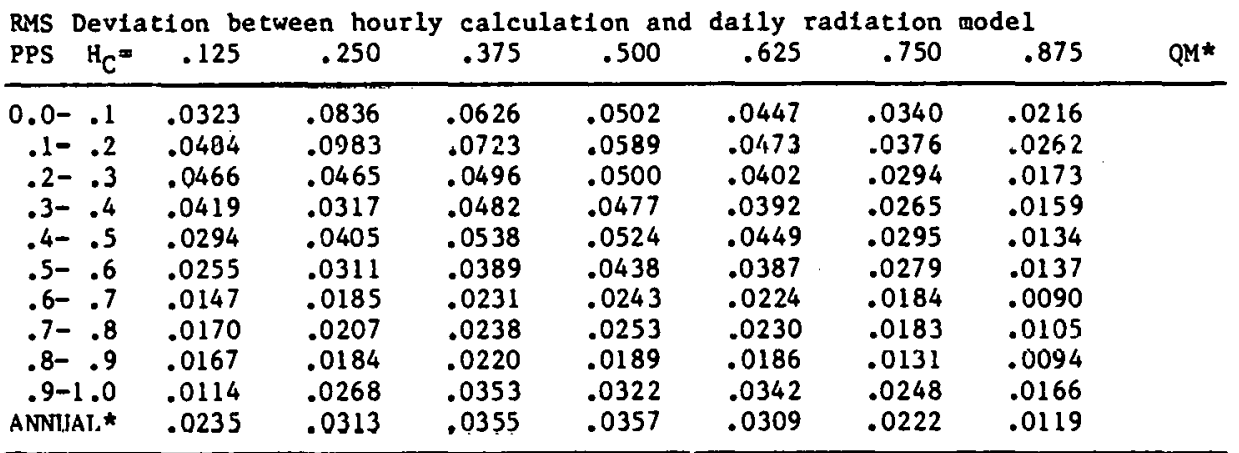

PPS - Dafly percent of possible sunshine

ND - Number of days with given PPS

$\mathrm{H}_{\mathrm{C}}=$ Critical radiation level set each day as a flxed percentage of $Q M$, the da1ly maximum insolation

H - Hourly calculation

D = Daily radiation model

ANNUAL* = Yearly average utilization and RMS deviation weighted by dafly total insolation. 
Table A-5. COLLECTOR UTILIZATION FOR VARYING HC LEVELS TYP ICAL METEOROLOGICAL YEAR, MADISON, WIS. MOD IFIED DAY LENGTH MODEL

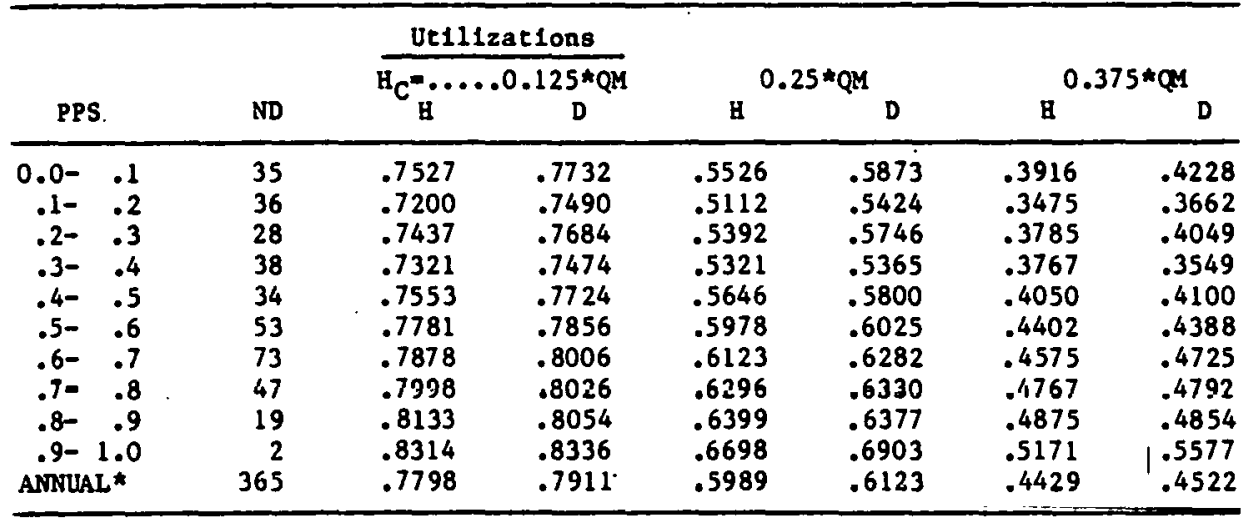

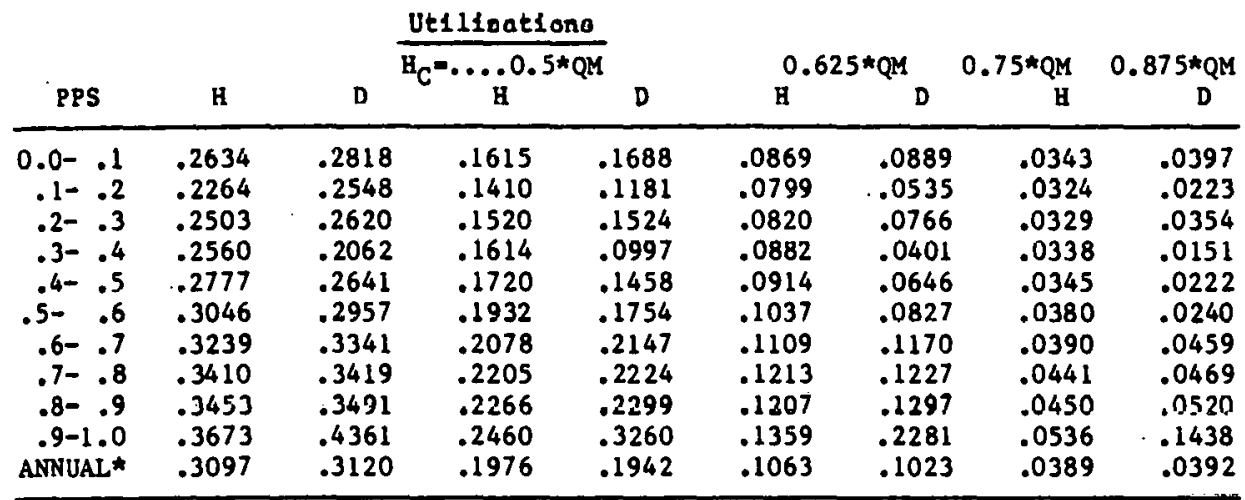

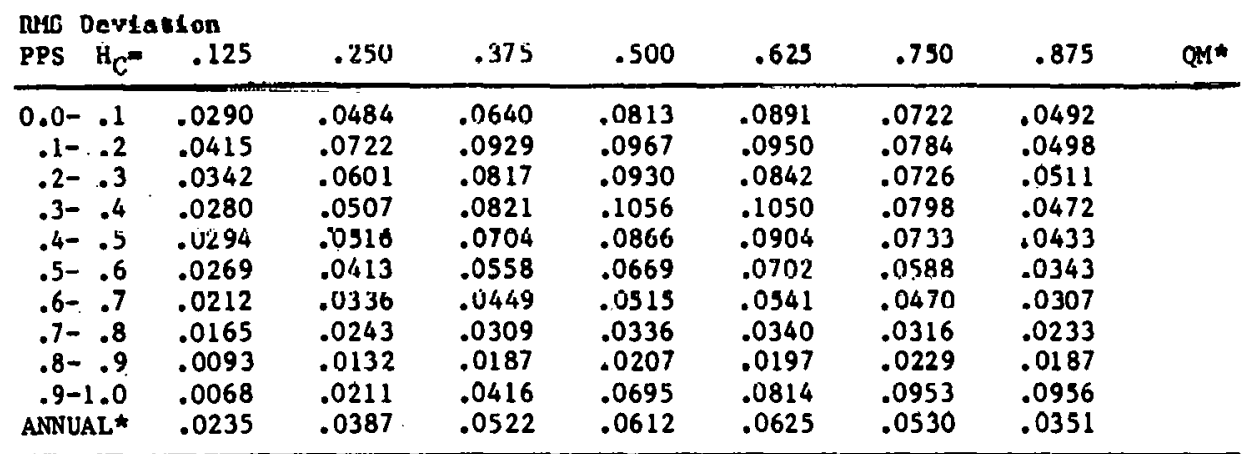

PPS = Daily percent of possible sunshine

ND = Number of days. with given PPS

${ }_{\mathrm{C}}$ - Critical radiation level set each day as a fixed percentage of $Q$, the daily maximum insolation

H - Hourly calculation

D = Dally radlation model

ANNUAL* - Yearly average uttlization and RMS devlation weighted by dally total insolation. 


\section{APPENDIX B}

\section{SOLAR HEATING DESIGN WITH THE DAILY ALGORITHMS}

In this appendix, detailed simulation methods using the daily algorithms will be described. The dally radiation model is assumed to be of the standard sinusoldal form

$$
Q(t)=Q_{k} \cos \omega t
$$

The parameters $Q_{k}$ and $w$ are set as described in the text. System simulation may be done in either daily or hourly intervals. For the given interval, the simulation consists of five steps.

(1) Solar heat collection is calculated based on a collector algorithm.

(2) Bullding heat and hot water load is efther calculated or input as data.

(3) Amount of solar heat supplied to the load is calculated using a storage-to-load heat exchanger effectiveness formula.

(4) Storage losses are calculated based on storage temperature, ground temperature, and overall storage U-value.

(5) End-of-period storage temperature is found by summing the heat flows to and from storage--collected solar heat, heat supplied to load, and storage losses--and dividing by the storage heat capacity.

Each of these steps will be described separately. A model based on hourly steps will be described initially because it is conceptually simpler than a model using daily steps.

\section{B. 1 COLLECTOR ALGORITHM USING HOURLY STEPS}

From equation 2-5, the hourly solar heat collection may be found as follows:

$$
\begin{gathered}
Q_{c o l}=F_{r}(\alpha \tau)\left(Q_{h}-H_{c}\right) \\
H_{c}=\frac{F_{r} U_{1}}{F_{r}(\alpha \tau)}\left(T_{o}-T_{a}\right) .
\end{gathered}
$$

In this equation, $\mathrm{U}_{1}$ is the collector heat loss factor, in $j o u l e s / \mathrm{hr} \cdot \mathrm{m}^{2}{ }^{\circ} \mathrm{C}$. The quantities $F_{r}(\alpha \tau)$ and $F_{r} U_{1}$ are typical collector performance parameters which must be input as data. The operating temperature $T_{0}$ is taken as equal to the storage temperature at the beginning of the period.

Lastiy, $\mathrm{T}_{a}$ is the average daytime amblent temperature. If only a dally average ambient temperature is available, $T_{a}$ may be set by adding $1.5^{\circ} \mathrm{C}$ to the daily average. 
$\Rightarrow 2 i_{i=j}^{i n}$

This leaves the hourly radiation $Q_{h}$ to be calculated according to the daily radiation model. The simplest method is to select insolation from the midpoint of the interval as average hourly insolation. Thus:

$$
Q_{h}=Q_{k} \cos \omega\left(t_{h}-\frac{1}{2}\right)
$$

where $t_{h}$ is the hour time at the end of the interval. This method results in a $2 \%$ overestimate of solar radiation compared to integration over the time interval. Integration would yield:

$$
Q_{h}=\frac{Q_{k}}{\omega}\left(\sin \omega t_{b}-\sin \omega t_{a}\right)
$$

where $t_{a}$ and $t_{b}$ are the beginning and end of period times, respectively, in hourly units and with solar noon set at zero. This hourly formula must be modified when the collector turn-on time and turn-off time falls within the interval in question. The following correction is added:

$$
\begin{aligned}
& \text { if } t_{a} \geq t_{x} \text {, then } t_{a} \text { is set equal to } t_{x} \\
& \text { if } t_{b} \geq t_{x} \text {, then } t_{b} \text { is set equal to } t_{x}
\end{aligned}
$$

where $t_{x}$ is the turn-on time calculated from Equation 2-11.

\section{B.2 BUILDING LOAD}

If buflding space heat load is not input as data, it may be calculated using the degree day method. This method uses the following equation:

$$
\operatorname{InAN}=I_{b}\left(T_{b}-T_{a}\right)
$$

where $T_{h}$ is a base temperature, usually $18^{\circ} \mathrm{C}$. The building heat loss coefficient, $U_{b}$, is typically one million joules/hour ${ }^{\circ} \mathrm{C}$ for a single $f$ amily house but would drop substantially for an energy efficient house.

The degree day method becomes increasingly inaccurate for energy-conserving houses, especially when passive solar gain is significant. Hot water load is ryplcally 30 million joules daily tor a single family residence, a figure which also could drop with increased energy efficiency.

\section{B.3 SOLAR HEAT SUPPLIED TO LOAD}

The solar heat supplied to load, calculated from the initial storage temperature, must be figured separately for space heat and hot water load. For space heat, the fraction of the load which is supplied by solar energy is equal to 


$$
f_{S H}=X_{h} \frac{T_{s}-T_{r}}{T_{r}-T_{a}}
$$

where $T_{s}$ is storage temperature, $T_{r}$ is room temperature, and $X_{h}$ is a heat exchange coefficient. This coefficient, typically of value 2 , is determined by the ratio of maximum heat exchange capacity per degree temperature difference to the building heat loss coefficient $\left(U_{b}\right)$.

The fraction of hot water which is supplied by solar is given by a similar formula:

$$
f_{H W}=c_{x} \frac{T_{s}-T_{c}}{T_{h}-T_{c}}
$$

where $T_{h}$ and $T_{c}$ are hot and cold water temperatures and $c_{x}$ is the heat exchange effectiveness from storage to load, usually 80-95\%.

\section{B.4 CHANGE IN STORAGE TEMPERATURE}

The heat flow into the storage tank during the interval is calculated by

$$
\Delta Q_{s}=Q_{c o l}-\text { solar load - storage loss } .
$$

The solar load and $Q_{c o l}$ have been found as described above. Storage loss is an additional term, found using an overall storage U-factor:

$$
\text { storage loss }=U_{s}\left(6 V_{s}^{2 / 3}\right)
$$

The term in parentheses approximates the storage surface area, in square meters, based on storage volume $\left(V_{s}\right)$ in $\mathrm{m}^{3}$. The storage U-factor, $U_{s}$, is typically equal to 360 joules $/ \mathrm{m}^{2}{ }^{\circ} \mathrm{C}$ for a buried tank.

Change in storage temperature for the period is found by

$$
\Delta \mathrm{T}_{3}=\Delta \mathrm{Q}_{\mathrm{S}} / \mathrm{V}_{\mathrm{G}} \mathrm{C}_{3}
$$

where $C_{S}$, the storage heat capacity, is $4.178 \times 10^{6}$ joules $/ \mathrm{m}^{3}{ }^{\circ} \mathrm{C}$.

The new storage temperature becomes the input to the calculation for the next interval. A flowchart for the simulation method with hourly steps is presented in Figure $B-1$. 


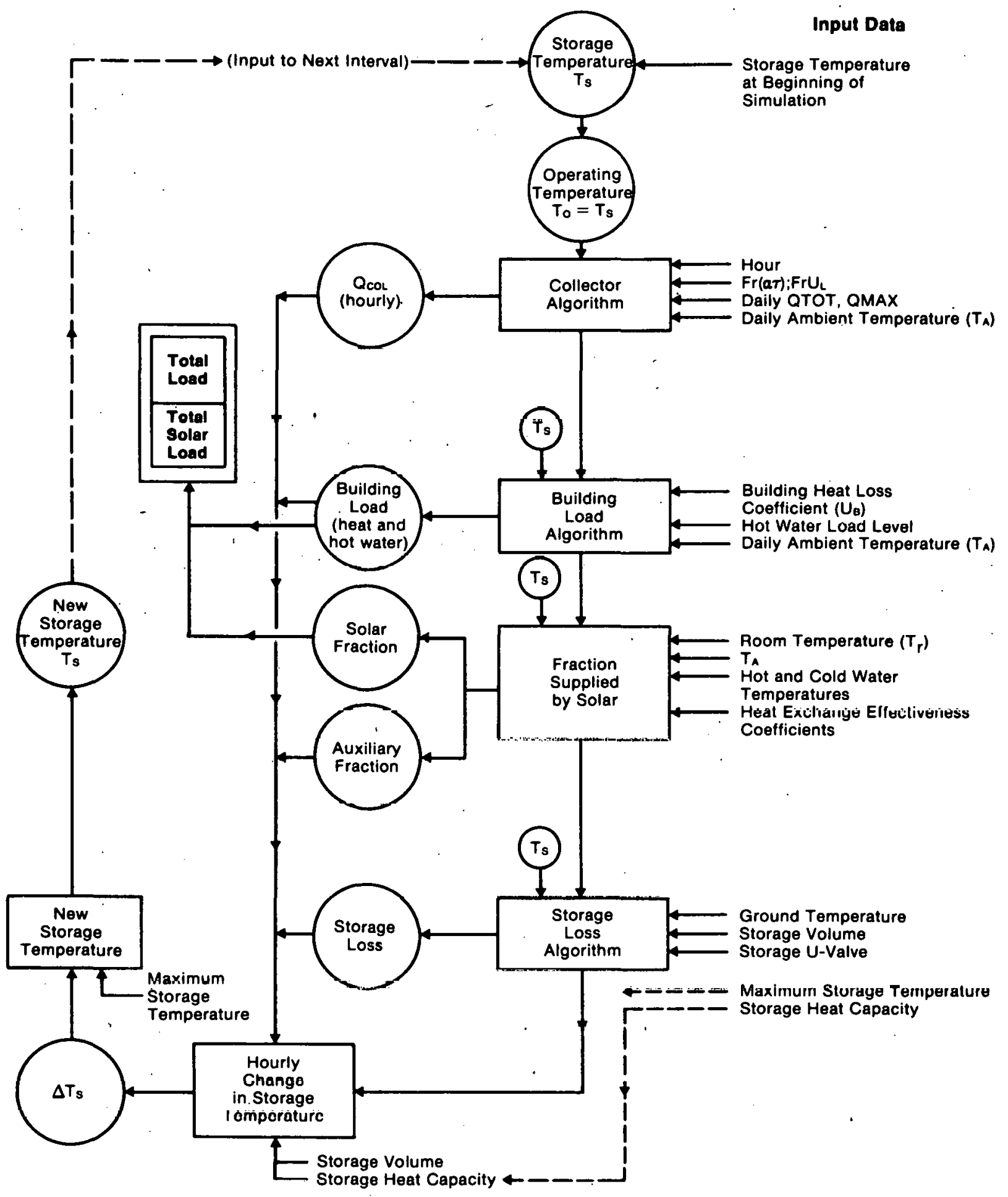

Figure B-1. Flowchart of Simulation with Hourly Intervals

Conventions: Boxes indicate calculations. Circles indicate calculated parameters, which may appear as input to a calculation (arrow leading away from parameter) or as the result of a calculation (arrow leading from calculation to parameter). Uncircled parameters, listed at the far right, are data inputs. The double box is the final result. 


\section{B.5 SIMULATION METHOD FOR SEASONAL STORAGE SYSTEMS}

For seasonal storage systems, the dally change in storage temperature is, at most, a few degrees so that hourly change in storage temperature may be safely ignored. Simulation may proceed with a dally time step as outlined in Sections B.1 through B.4. The collector algorithm for the entire day is based on Equation 2-13 with the critical level held constant:

$$
Q_{c o 1}=F_{r}(\alpha \tau)\left(Q T O T \sin \omega t_{x}-2 t_{x_{c}}{ }_{c}\right)
$$

with the turn-on time calculated according to Equation 2-11. All other steps remain the same, except that load and storage losses are calculated for a day rather than for an hour.

\section{B.6 SIMULATION METHOD WITH DAILY STEPS FOR SMALL STORAGE TANKS}

When the storage tank is sma11, storage temperature changes too fast to permit a direct simulation with daily steps. A daily step simulation may be performed using an teration as follows.

(1) Collector gain and daytime load are calculated, assuming that operating temperature remains equal to the initial storage temperature all day. Equation $B-10$ is used, with $\mathrm{H}_{c}$ assumed constant. The end-of-day storage temperature is calculated as in Section B.4, and average daytime storage temperature assumed midway between the beginning and end of day storage temperatures.

(2) Collector gain and daytime load are recalculated, assuming that storage temperature changes through the day as found in step 1. Collector turn-on time $\left(t_{1}\right)$ is the same as in step 1 , but a new turn-off time $\left(t_{2}\right)$ is found using equation $2-11$ with the final storage temperature from step 1. The new algorithm is:

$$
Q_{c o l}=F_{r}(\alpha \tau) \cdot \frac{Q T O T}{2}\left(\sin \omega t_{1}+\sin \omega t_{2}\right)-\left(t_{1}+t_{2}\right) H_{c} \cdot(B-11)
$$

The critical level $\mathrm{H}_{c}$ in Equation $B-11$ is calculated as in Equation B-5 with the operating temperature $\left(T_{0}\right)$ set equal to the average daytime storage temperature calculated in step 1. The fraction of solar heat supplied to load is also calculated, assuming storage temperature is equal to the average daytime temperature from step 1. Final daytime sturage temperature is again found as in Section B.4.

(3) Nighttime system performance is calculated by using the same two-step iteration to estimate the fraction of the load supplied by solar heat. The procedure is the same as in step 1 and 2 with collector gain set equal to zero.

A flowchart of this method is presented in Figure $B-2$. 


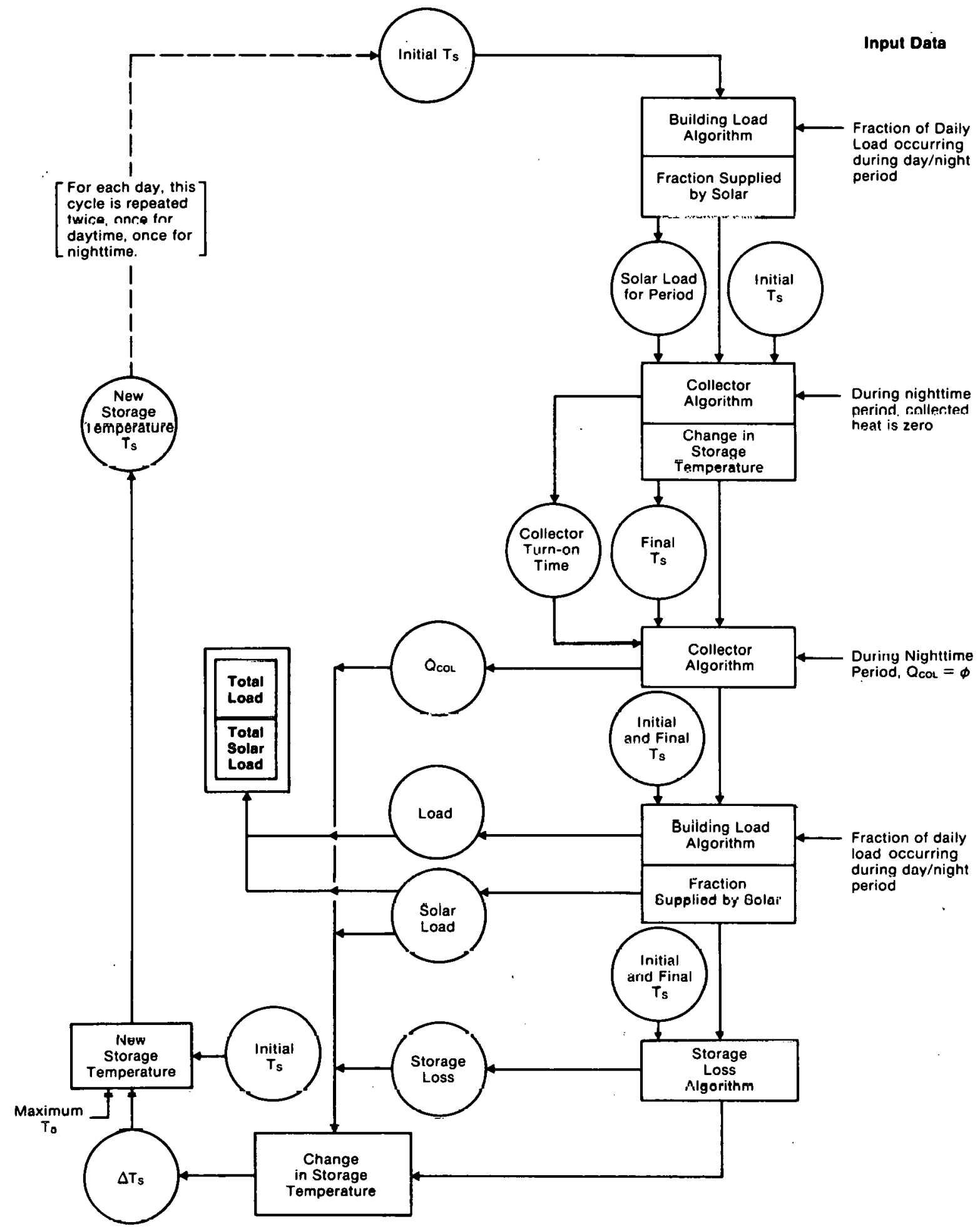

Figure B-2. Flowchart of Daily Simulation

Conventions are the same as in Figure B-1. Data inputs which are identical to those in Figure B-1 have been omitted in this flowchart. All calculations in this flowchart require the same data inputs as shown in Figure B-1.

This simulation runs twice for each day for the daytime and nighttime periods. Collector algorithm is bypassed for the nighttime period. 


\section{B.7 SIMULATION OF THE "TWO TANK" SYSTEM}

The simulation of the "two tank" system is similar to the method outlined in Section B.6, with the following differences.

- Steps 1 and 2 are performed for the small storage tank. However, the final operating temperature calculated in step 1 and used in step 2 is constrained to be no greater than the temperature of the seasonal storage tank. The average daytime temperature for the small tank is calculated with the constraint that the storage temperature does not exceed the temperature of the seasonal tank.

- At the end of step 2, the end-of-day storage temperature is found differently. The net flow of heat into storage is added to the small storage tank, but this tank is again constrained to remain below the temperature of the seasonal storage tank. If the net heat flow into storage is too large to be added to the small tank, the remainder of the collected solar heat is added to both the small tank and the seasonal tank in proportion to their volumes. This assures that the temperature of the small tank never exceeds the temperature of the seasonal storage tank.

- In steps 2 and 3 , the capacity of the small storage tank to meet the load is assessed as described in section B.6. If the small storage tank is unable to meet the entire load, the remainder of the load is supplied by the seasonal storage tank. The system design assumes a separate heat exchanger for each storage tank. Consequently, if the two tanks together are insufficlent to meet the load, the percentage supplied by solar energy is found by adding the percentage supplied by each tank separately.

\section{B.8 CALCUlation OF THE DAY LENGTH}

The following is a method for calculating the day length $\left(t_{D}\right)$ used in the daily radiation algorithm (Duffie and Beckman 1974).

Necessary inputs are the latitude $\phi$, collector slope $s$, and the declination $\delta$. It is assumed that the collector faces due south.

Declination is calculated from

$$
\delta=0.4095 \sin 2 \pi \frac{284+n}{365}
$$

where $n$ is the number of the day of the year, January 1 being equa1 to 1 , and all angles are in radians. The day length is given by

$$
t_{D}=\frac{12}{\pi} \arccos (-\tan \phi \tan \delta)
$$


A south-facing collector will, however, be shaded for large parts of the morning and late afternoon during the summer when the sun is in the northern half of the sky. This shading reduces the effective day length of a south facing collector. The effective day length is constrained by

$$
t_{D}=\frac{12}{\pi} \arccos [-\tan (\phi-s) \tan \delta]
$$

Effective day length 1s, thus, the minimum of the values of Equations $B-13$ and B-14. With a collector tilt equal to the latitude, this means that the day length can never exceed 12 hours. 


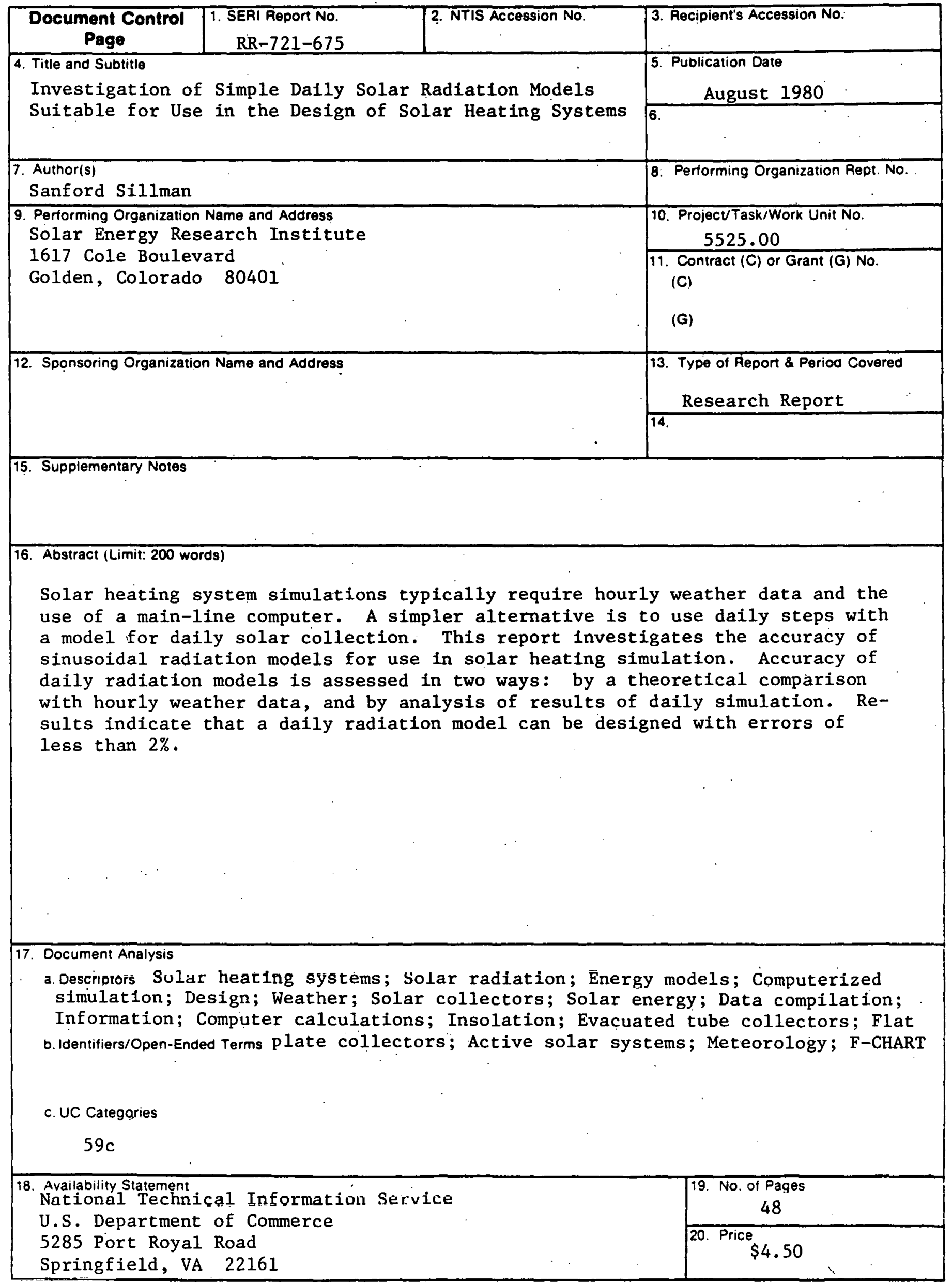

